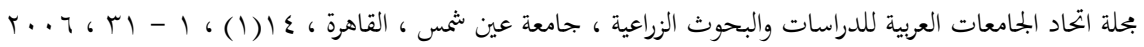

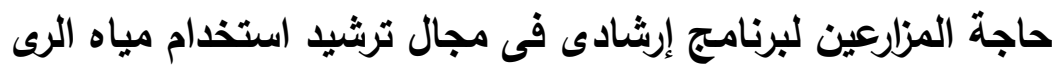

وإدارة نظم الرى الحديث للمنتفعين بمشروع

درب الأربعين - محافظة الوادى الجديا

[1]

محمود محمد مصطفى معوض'

الملخص

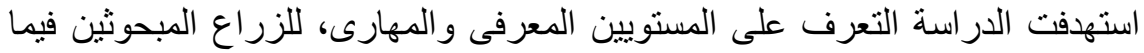

يتعلق بالتوصيات الفنية الخاصة بترشيد استخدام مياه الرى ونظم إدارتها المختلفة، وتحديد التهايدا

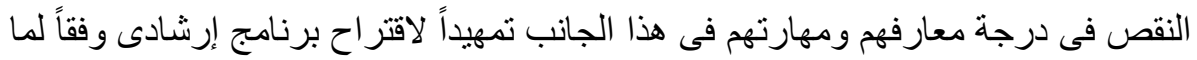

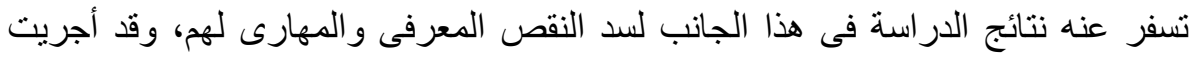

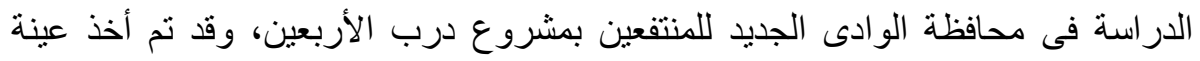

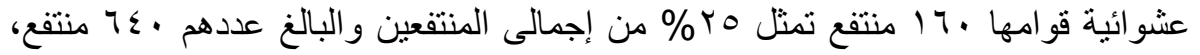

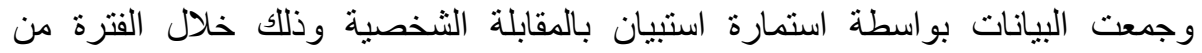

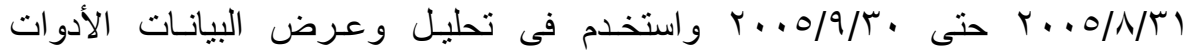

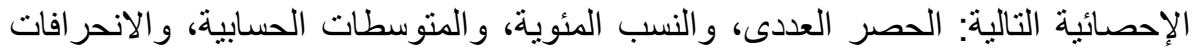

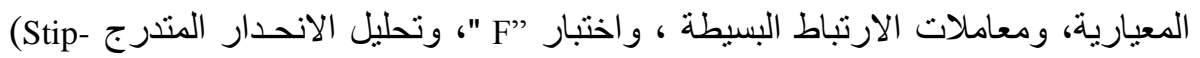
. وise) - - أن أكثر من نصف عينة المبحوثين r, ب07\% كانت معارفهم منخفضة فيما يتعلق

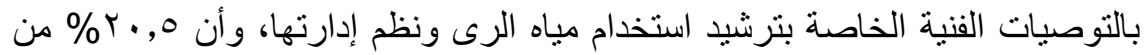

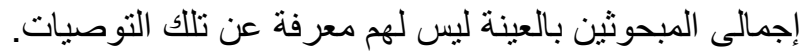

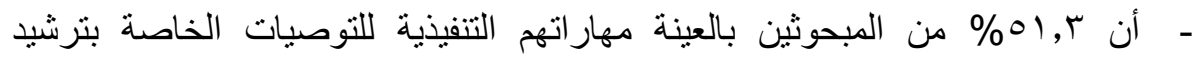

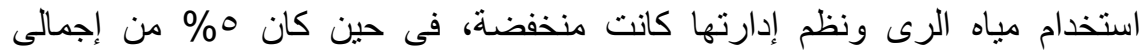
المبحوثين مهار اتهم فى هذا الثأن مرتفعة.

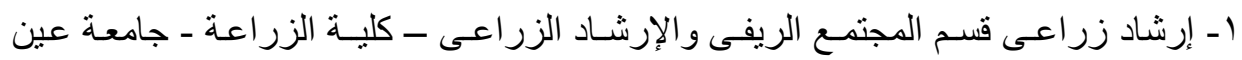
شمس، شبرا الخيمة، القاهرة

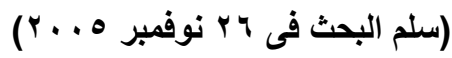

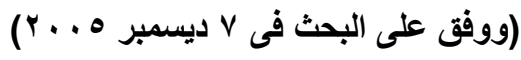


- أن هنالك نقص معرفى فى نحو سبعة مجموعات من التوصيات الفنية المتعلقة بترشيد

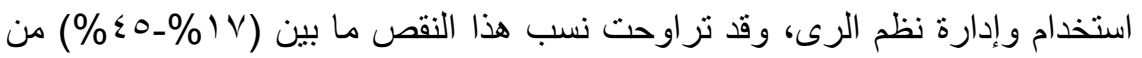

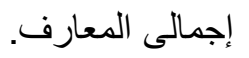

- أن هنالك نقص مهارى لدى المبحوثين فيما يتعلق بالتوصيات الفنية المتعلقة بترشيد

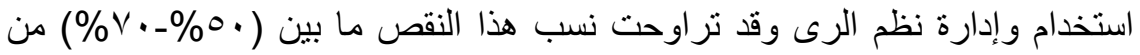

$$
\text { إجمالى المهار ات التنفيذية. }
$$

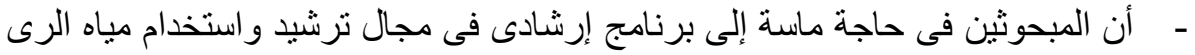

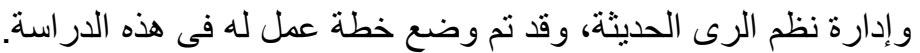

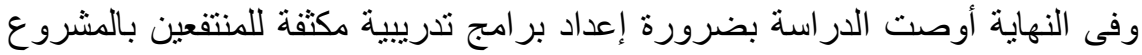
لرفع المستوى المعرفى و التنفيذى لهم فى هذا الثنأن.

الكلمات الدالة : حاجـة المزارعين ، برنامـج إرشادى ، ترشيد استخدام مياه الرى ،

$$
\text { مشروع درب الأربعين }
$$

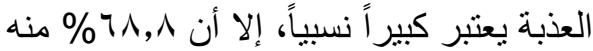

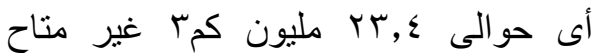

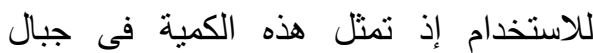
الجليد. كما يقدر حجم المياه المالحة بنحو

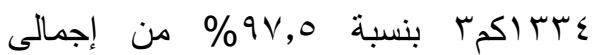

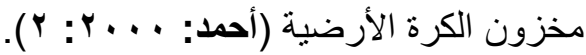

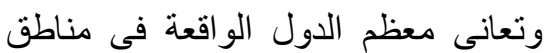

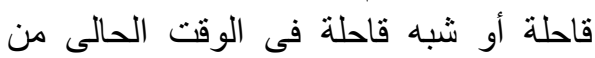

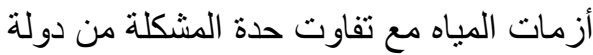

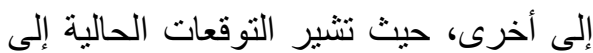

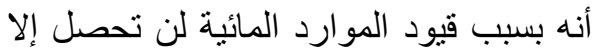

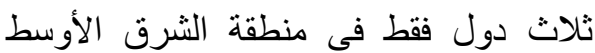

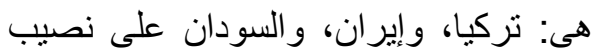

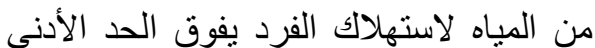

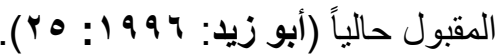

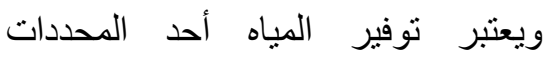
الرئيسية اللازمة لعمليات التوسع الزراعى، الزئ

\section{مقدمـة}

تعد الأرض و المياه من أهم محددات

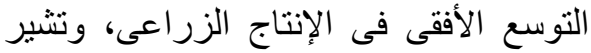
البيانات والإحصاءات إلى الإتى محدودية هذين الزين

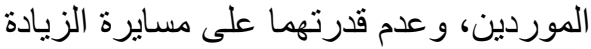

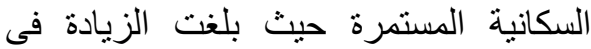
أعداد السكان المستمرة خلال قرن من الزمان بنحو ستة مرات، فى حين بلغت الزيادة الزية

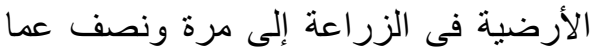

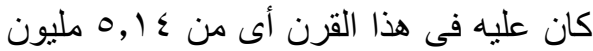

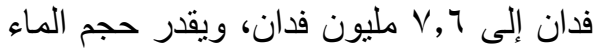

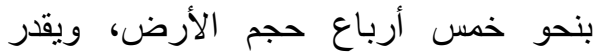

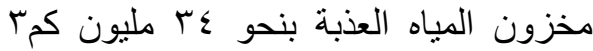

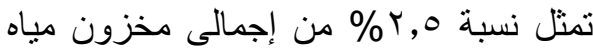

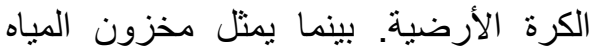

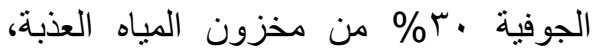
وعلى الرغم من أن ذلك المخزون من المنياه 
تطوير وتتظيم وترشيد استخدام مياه الرى،

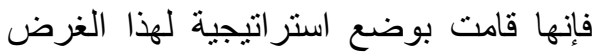
بهدف الوفاء بخطة التنمية الاجتماعية والاقتصادية معتمدة فى ذلك الوفاء على محاور

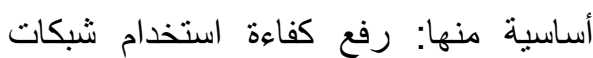

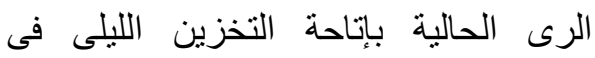

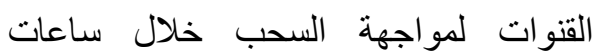
الذروة بالنهار، و إنشاء المساقى المطورة المباء

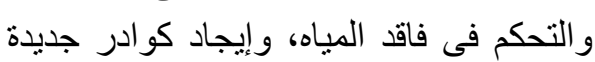
من المهندسين الزر اعيين و المرشدين العاملين

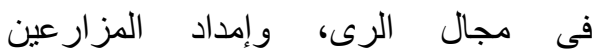

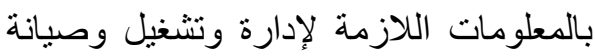

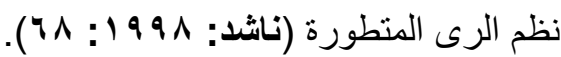
لذا فإن هنالك مجهودات تبذل حالياً ومستقبلاً ترتكز على تطوير وسائل استخدام الموارد المائية المتاحة بإدخال أساليب التقنية الحديثة

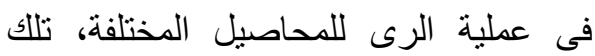
الأساليب التى من شأنها نوفير المياه لرئ لرى الرئي

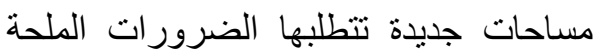

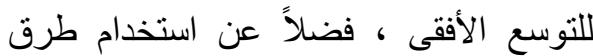
الرى الحديثة كالرى بالرش، و الرى بالرى بالتنقيط

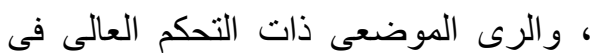
كميات المياه اللازمة، مما يؤدى إلى الـى الإقلال

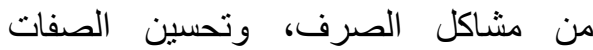
البنائية للتربة، و وانخفاض منسوب المناء

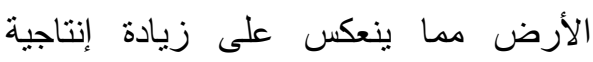

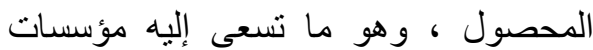

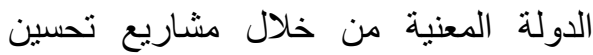
التربة، وتحديث العمل المزرعى، و وإنثاء

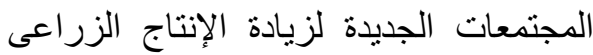

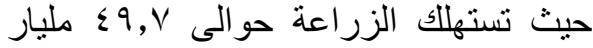

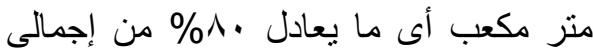

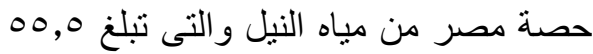

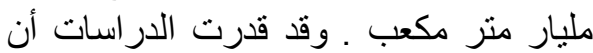

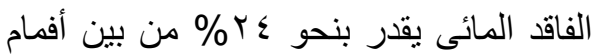

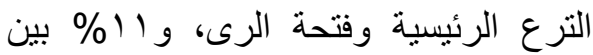

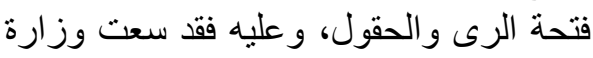

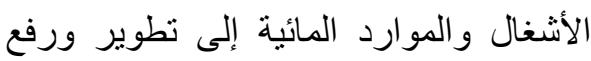
كفاءة نظم الرى فى حوالي 7 مليون فدان خلال عشرون عاماً وذلك بتحديث شيكات الرئ

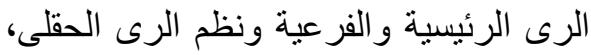

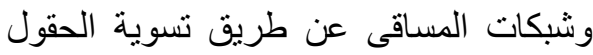
وتبطين المساقى، واستخدام خطوط الأنابيب

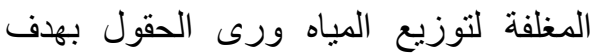
استغلال مياه الرى استغلالاً مثالياً مع منع الرّاء الإسر اف وتقليل الفاقد، وبناءًا عليه فقد صدر الرّاليا

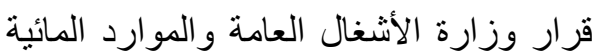

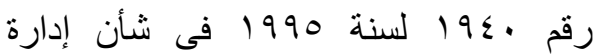
وانتفاع الزراع بنظم الرى الحقلى المتطور

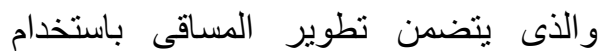
إحدى أساليب الرى المطورة، و التى نتمثل بلتيل فى ضيخ مياه الرى في الرى مساقى مبطن

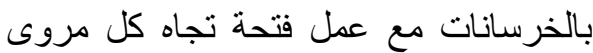

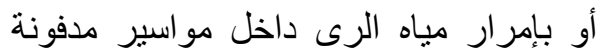

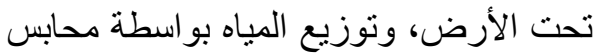

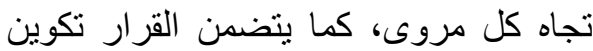

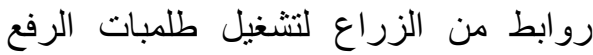

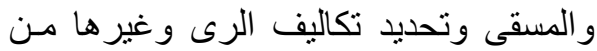
الأعمـال (وزارة الأشغال العامة والئ والموارد

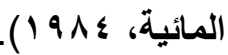
وحرصاً من الدولة على تحقيق أقصى المى المئي

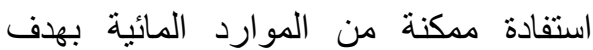


حاسماً للغاية المستقبلية للتنمية الزر اعية، إلا لإناهية

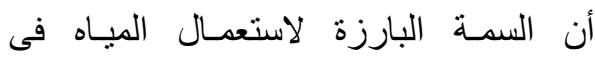
الزراعة فى الوقت الحاضر هـى ارتفاع نسبة لإنية

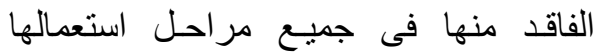
وخاصـة فى الزراعة مما فيترتب علئ عليه

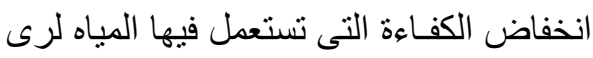
الأر اضى الزراعية، ويرجع ذلك إلى إلى أربعة

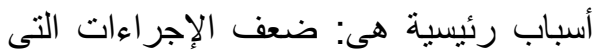

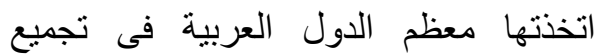
وتطوير وتخزين مياه الرى و الوديان أثناء موسم الفيضان، و واستعمال الطرق البديائية فى الري

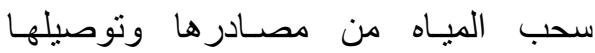

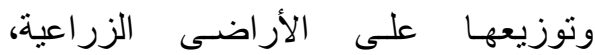
واستعمال الطرق البدائية فى إضافية الرياه

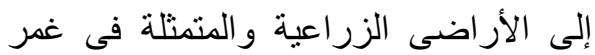

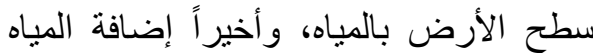

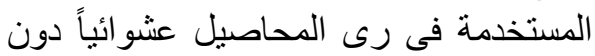
الاعتماد على تجارب لتقدير كمية المياه

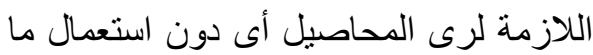

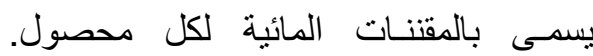

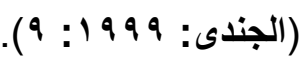
وقد تعددت المؤتمرات والدراسات

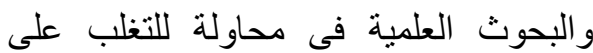
المشاكل السابق ذكرها وترشيد استخدام مياه

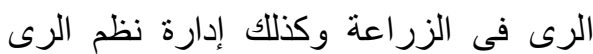

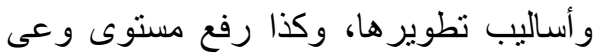

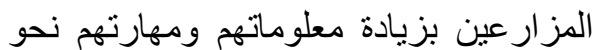

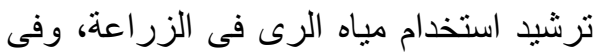

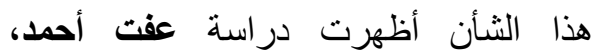

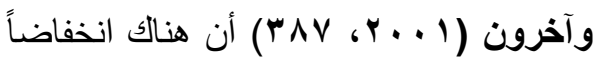
ملحوظاً فى المستوى المعرفى بأساليب
بشقيه النباتى و والحيوانى وتحقيق الأمن الغذائى (سعد: 1999 (V) (V) وقد بدأت الدولة خطتها للعشرين عامَاً

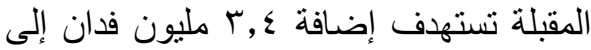

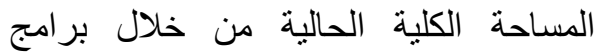

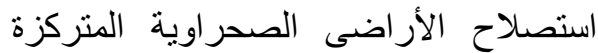

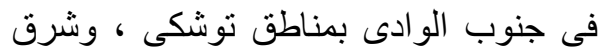

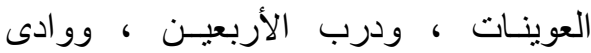

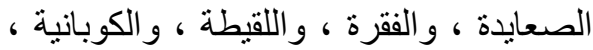

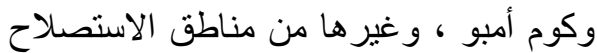

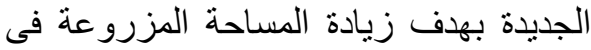

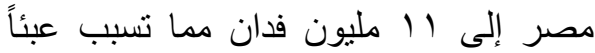

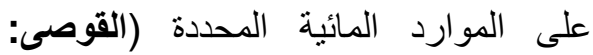
( )

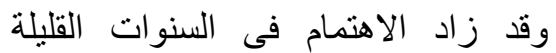

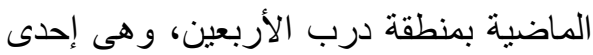
المناطق الو اعدة بمحافظة الو ادى الجديد حيثة وهيث الجيث تقع جنوب مدينة الخارجة بمسافة نحو مائة النة

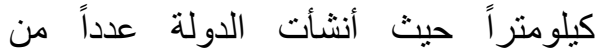
المزارع وحفرت الآبار و وأقامت القرى الته، واستقدمت الكثير من المزارعين من الإر والوادى القرى

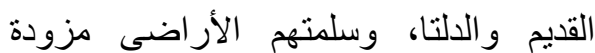
بالآبار الجوفية وشبكات الرى الحديثة. كما

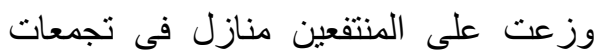

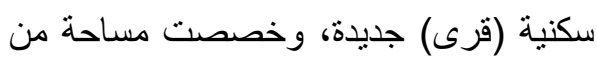
الأرض لكل أسرة بهدف جذب وخد المو اطنين إلى الى

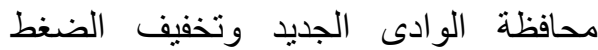

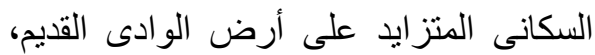

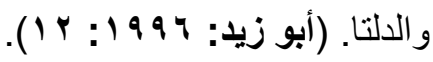

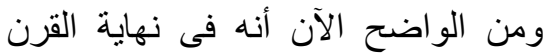
الحالى ستصبح المياه بلا جدال مصدراً 
ترشيدها وكيفية صيانة شبكات الرى ونظم

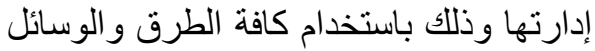
الإرشادية فى المواقف التعليمية المناسبة

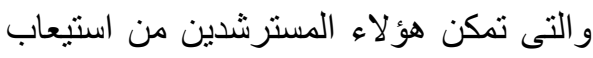

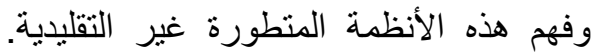

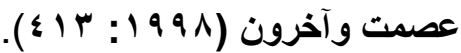
وفى هذا الثأن أوضح (198)

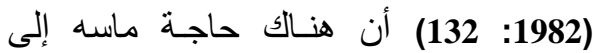

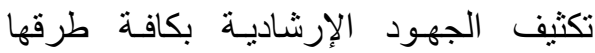

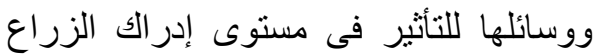

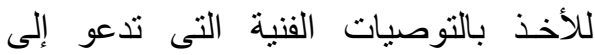

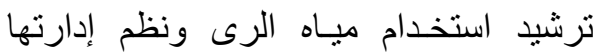
وخاصة فى المناطق المستصلحة.

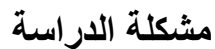

تعتبر تنمية مصادر المياه وترشيدها

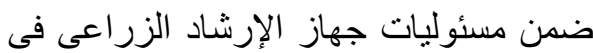

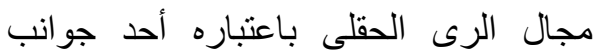

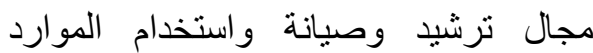

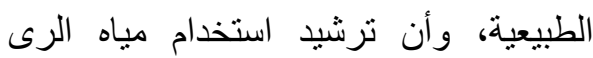

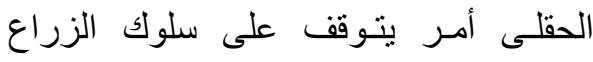

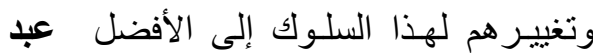

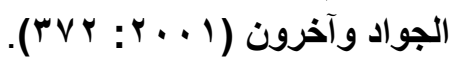

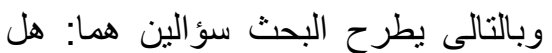

لدى المنتفعين بمشروع درب الأربعين تحت الئ

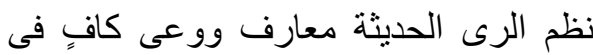
كيفية التعامل مع تلأك النظم و إدارتها بأسلوب

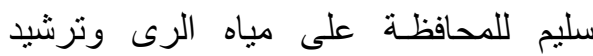

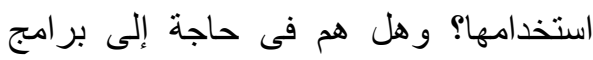

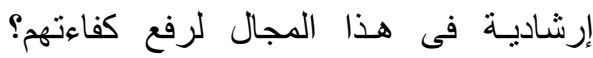

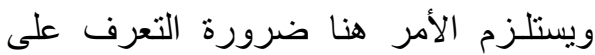

وطرق ترشيد الرى، وكذا تدنى مستوى تنفيذ الزراع بالتوصيات الخاصة بترشيد الزيد استخدام

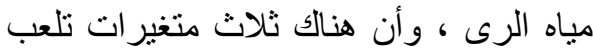

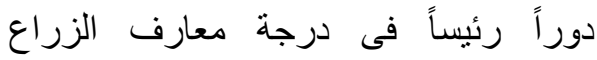

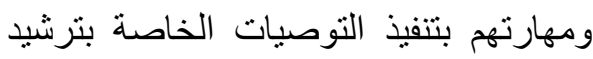

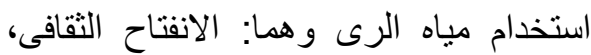

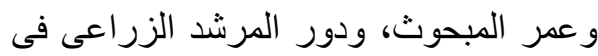

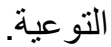

فى حين أوضحت دراسة عبد الجواد،

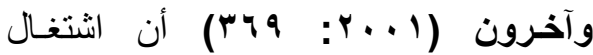
المرشدين فى مشروع تطوير الرئ الرى أدى إلى

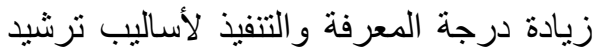

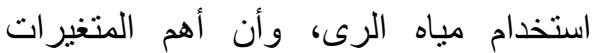
الأكثر تأثثيراً على زياه الري، وان درجة المعرفة الثغيرات

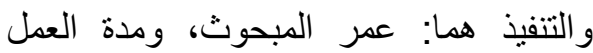

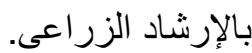
وقد اتفق كل من أبو السعود، وآخرون وآنادي (991 (991)

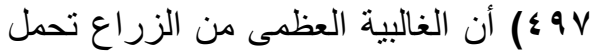
اتجاهاً قوياً نحو ترشيد استخدام مياه الرى، الزي، و هناك فروق معنوية بين مجموعات الزئ الزراع من حيث درجة المعرفة والتنفيذ، و والاتجاه

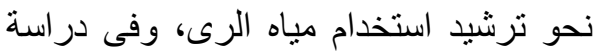

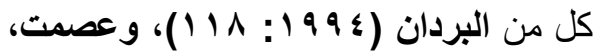

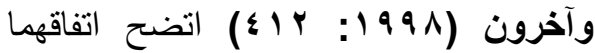
على أن غالبية الخريجين المبحوثين يدركون

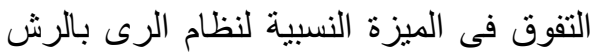
على النظم التقليدية الأخرى.

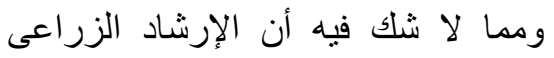
يتحمل عبء نشر المستحدثات الزر اعية ومن الإن الزراعي بينها استخدام طرق الرى الحديثة وأساليب 
0- تحديـ مجموعة التوصيـات الفنيـة المتعلقة بترشيد استخدام مياه الرى مجئ ونظم إدارتها التى يعانى منها الزراع منياه المبحوثين من مشكلات نقص المعرفة لماني ب. 7- اقتراح خطة عمل برنامج إرشادى

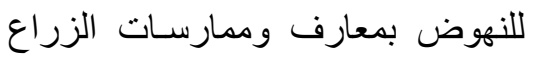
المبحوثين نحو ترشيد استخدام مبياه الرى ونظم إدارتها بناءًا على ما تسفر نئر عنه نتائج الهدف ولطم السابق.

\section{فروض الدراسة}

لتحقيق أهداف الدراسة الثالث و الرابع تم صياغة الفروض النظرية التالية الفرضين النظريين الأول والثانى: "يوجد فرق ذو دلالة معنوية بين كل من منغيرات

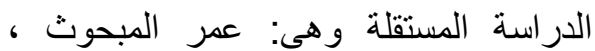

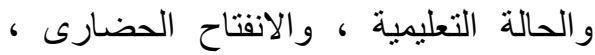

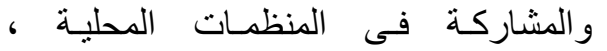
و التعرض لوسائل الاتصال الجماهيرية ، التهارية

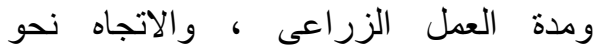
المستحدثات الزراعية ، والاتصال بوكلاء

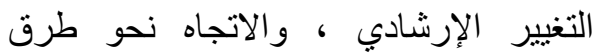
ترشيد مباه الرى ، ومشاركة المبحوثين فى الإنى إدارة وصيانة شبكات الرى، وبين المستوينين ويناه

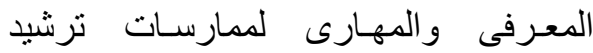

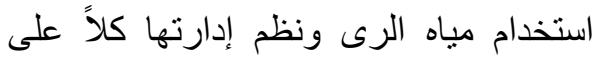

$$
\text { حدة. }
$$

الفرضين النظريين الثالث والرابع: يسهم كل متغير من المتغيرات المستقلة التالية: عمر المبحوث ، و الحالة التعليمية، و الانفتاح
مستوى معارف ومهارات الزراع فى هذا

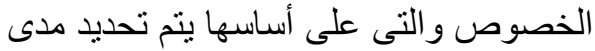

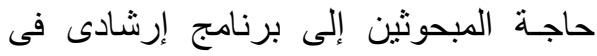
مجال نرشيد استخدام مياه الرى وإدارة برني

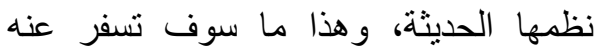
نتائج الدراسة الر اهنة.

\section{أهـداف الار اسـة}

فى ضوء أبعاد المشكلة السابق عرضها فقد أمكن صياغة أهداف الدراسة الر اهنة فيما ا- التعـرف على المستوبين المعرفى و المهارى للزراع المبحوثين فيما يتعلق بالتوصيات الفنية الخاصة بتريد استخدام مياه الرى ونظم إدارتها المختلفة. Y- تحديد النقص فى درجـة المعـارف و المهار ات للزر اع المبحوثين فيما يتعلق

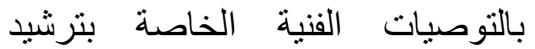
استخدام مياه الرى ونظم إدارنها. r- تحديد علاقة بعض المتغيرات الثخصية و الموقفية المستقلة للمبحوثين المنتفعين بمنطقة الدراسة بمستوى معارفهم ومهارتهم لممارسات ترشيد استخدام مياه الرى ونظم إدارتها. ـ- تحديد درجة إسهام المتغيرات الثخصية

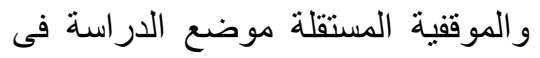

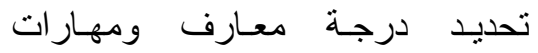
المبحوثين لممارسات ترشيد استخدام مياه الرى ونظم إدارتها. 
بيعض المعارف الخاصة بالأساليب المرتبطة

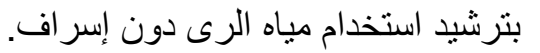
تنفيذ الممارسات الخاصة بترشياه الريد مياه الرى : ويقصد بها مدى التطبيق الفعلى المئى

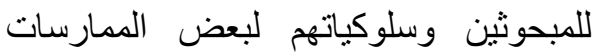
الزراعية المرتبطة بأساليب استخدام مياه الرى وطرق إدارتها.

\section{ثانياً: المجال الجغرافى للاراسة}

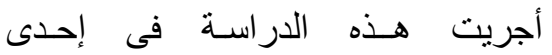

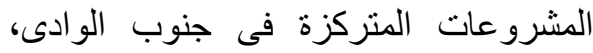

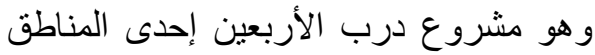
الواعدة بمحافظة الو ادى الجديد والتى دئ تبعد التيد مائة كيلومتر جنوب مدينة الخارجة كمجالاً جغر افياً للار اسة.

ثاثثاً: المجال البشرى للاراسة

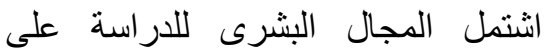

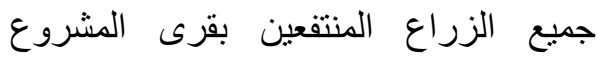
والبالغ عددها أربعة قرى حيث بلغ بلغ جملة المبن

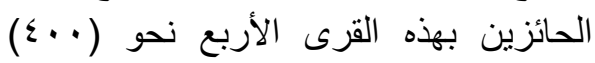
منتفع.

\section{رابعاً: المجال الزمنى للاراسة}

تم جمـع البيانـات خـلال الفترة من

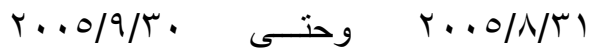

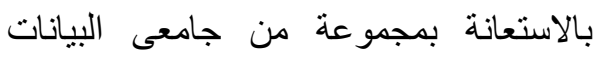
المدربين تدريباً كافياً. خامساً: عينة الاراسة
الحضـارى ، و والمشاركـة فى المنظمات المحلية ، و التعرض لوسائل الاتصل التصال

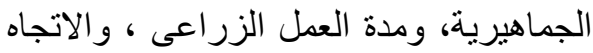

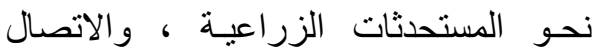

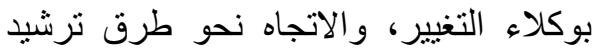
مياه الرى، ومشاركة المبحوثين فى إدئ إدارة

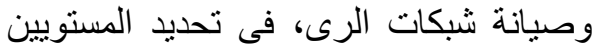

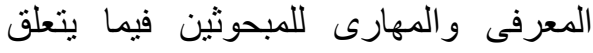
بالتوصيات الفنية فى مجال ترشيد استخدام مياه الرى ونظم إدارتها كلاً على حدة.

\section{الطريقة البحثية}

تضمنت الطريقة البحثية للاراسة على البه

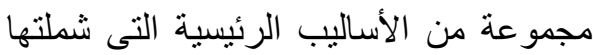

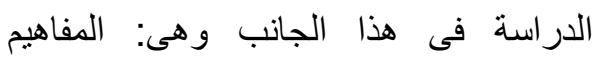

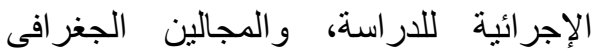

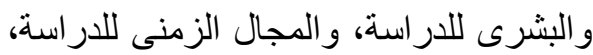

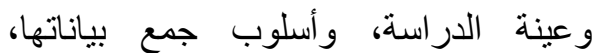
والمعالجة الكمية للبيانات، وأخيراً أدوات التيات التحليل الإحصائى المستخدمة فى الدراسة. أولاً: المفاهيم الإجرائية ترشيد استخدام مياه الرى: ويقصد به فى الري هذه الدراسة كيفية تنظيم استخدام مياه الرى الرى

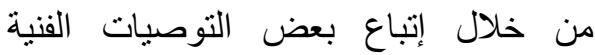

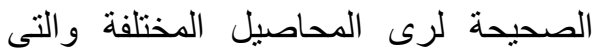
يمكن من خلالها توفير الاحتياجات الإروائية للمحاصيل المختلفة دون إسر اف. المعرفة بأساليب وطرق ترشئ المبرف مياه الرى : ويقصد بها مدى إلمام المبحوثين برئ 
عرض مجموعة التوصيات الفنية على من لرئ

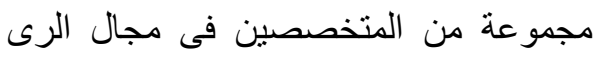
بوزارة الرى و الموارد المائية، و وأساتذة التئ الجامعات المتخصصين فى هذا المجال، وقد الردان

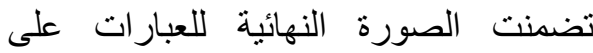
البنود التى وافق عليها غالبية المحكمين، والتى كونت العبار ات فى صورتها النهائية،

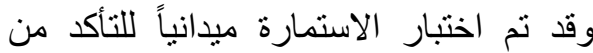

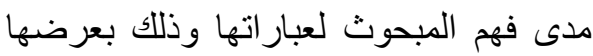

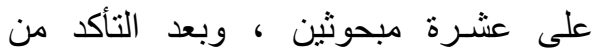
مستوى فهم المبحوثين وإجراء عمليات التعديل أو الإضافة أو الحذف أصبحت

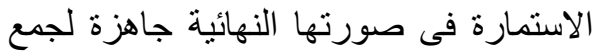
البيانات الميدانية. وقد تم جمع البيانات الميدانية بالمقابلة الثخصية وذلك بعد تدريب مجموعة من لئ

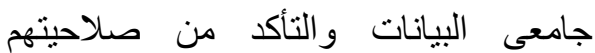

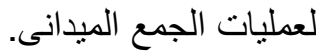

سابعاً: المعالجة الكمية للبيانات بعد الانتهاء من عمليات جمع البيانات تم ترميزها و إعطائها الأوزان الرقمية المناسبة الانية

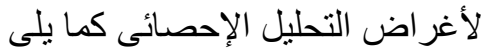

\section{1 - متغيرات الاراسة التابعة}

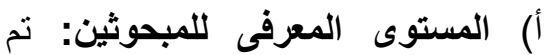
قياسه من خلال ثلاثون عبارة لقياس المستوى المعرفى يستجيب إليها المبحوثين

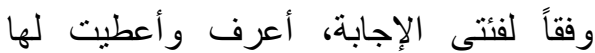

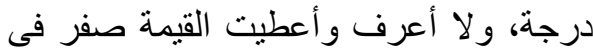
حالة العبارات الموجبة، وتعكس فى حالة اعلة
تم اختيار عينة من شاملة الدراسة بلغت

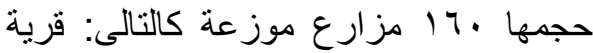

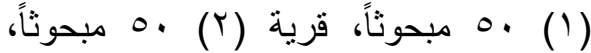

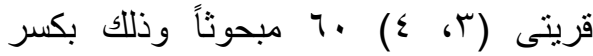

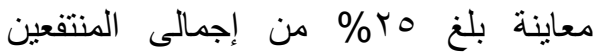
بالمشروع نم اختيار هم بطريقة عشو ائية من

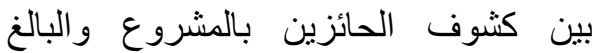
عددهم ·ـ آ مز ارعاً. سادساً: أسلوب جمع بيانات الدراسة اعتمدت الدراسة على استمارة استبيان

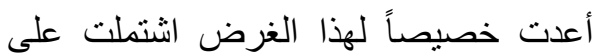

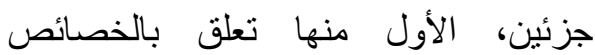

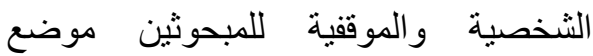
الدراسة وهى: عمر المبحوث، و والحالة التعليمية، و الانفتاح الحضارى، و والمشاركة

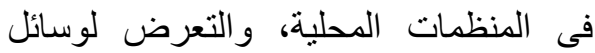

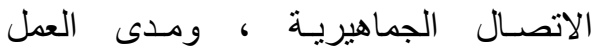

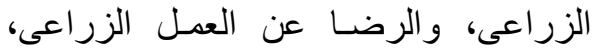

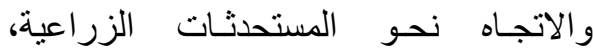

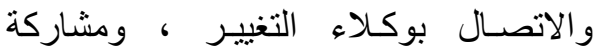
المبحوثين فى إدارة وصيانة شبكات الرىى،

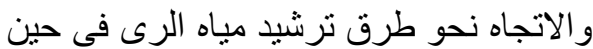

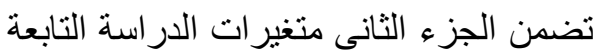

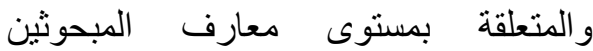

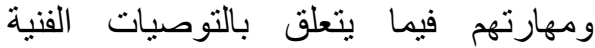
المتعلقة بترشيد استخدام مياه الرى ونظم إدارتها، وقد تضمنت نحو 00 عبارة تدور جميعها حول ترشيد مياه الرى ونظم إدارتها.

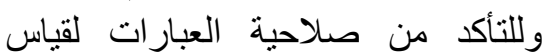
المستوى المعرفى والمهارى للمنتفعين تم 


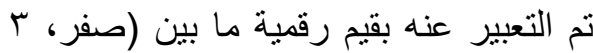

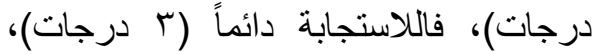

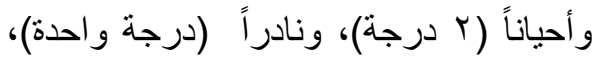
ولم يتردد (صفر درجة)

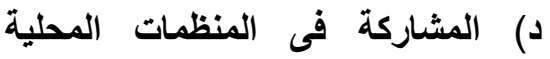

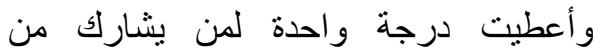

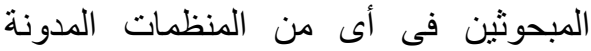

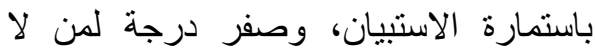
يشارك فى أنشطنها.

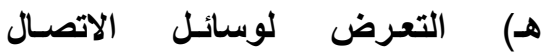
الجماهيرية: وتم قياسه بالدرجة الكلية التى لالى

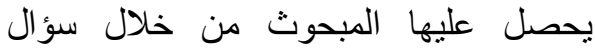
المبحوثين عن مدى تعرضهم لوسائل

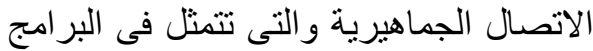

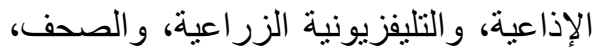

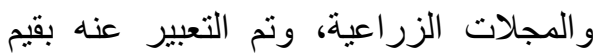

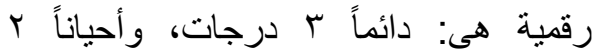

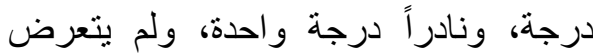

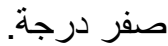
و) مدة العمل الزراعى: تم حسابه بعدد

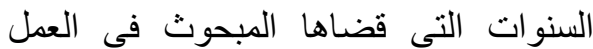
الزر اعى قبل وبعد استلام أرض المشات المشروع.

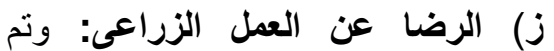
حسابه بواسطة الدرجة الكلية التى يحصل الزفل عليها المبحوث من خلال استجاباته لعبار ات التهات

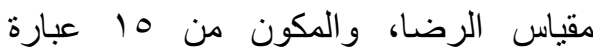
نصفها إيجابى والنصف الآخر سلبى، وقد الندان

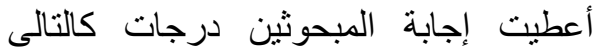

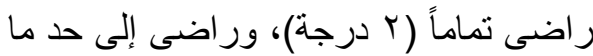

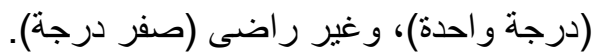

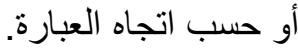

الإجابة السالبة، وبحساب الدرجة الكلية لتعبر عن درجة المكون المعرفى للمبحوثين.

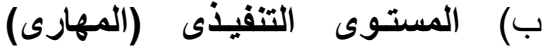
للمبحوثين: وتم قياسه من خلال خمسة التهات وعشرون عبارة تتعلق بالتوصيات الفنية المتعلقة بترشيد استخدام مياه الرى ونظم إدارتها بستجيب إليها المبحوثين وفقاً لفئنى الرئي

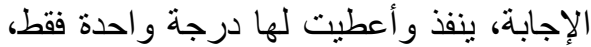
ولا ينفذ وأعطيت القيمة صفر وذللك فى حالة الإجابة الموجبة للعبارة، تعكس فى حالة الإجابة السالبة، وتم حساب الإدجة الدابة الكلية لتعبر عن درجة المكون التنفيذى (المهارى)

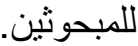
r- المتغيرات المستقلة للاراسة أ) عمر المبحوث: وقد تم حساب عمر المبحوث بالرقم الخام لأقرب سنة أثناء جمع

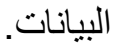
ب) الحالة التعليمية: وقد تم حساب الحالة التعليمية بعدد سنوات التعليم الرسمى، أتطي، حيث أعطيث للأمى صفر درجة، ويقرأ

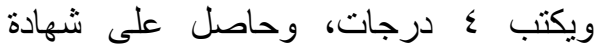
الابتدائية أعطيت له 7 درجات، وحاصل ولاصل على الإعدادية وأعطيت لله 9 درجاته وحاصل على الثانوية العامة وما بعادلها لهاديا وأعطيت له با درجة، وحاصل على مؤهل

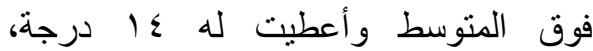
وحاصل على مؤهل جامعى و أعطيت له اعله 17

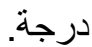
ج) الانفتاح الحضارى: ويقصد به مدى تردد المبحوثين على المناطق الحضرية، وقداح 
الرقمية المناسبة لأغراض التحليل، وقد تم

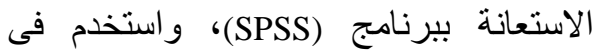
عرض البيانات الإحصائية كل مما يأنى

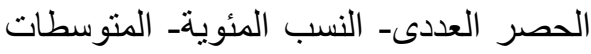

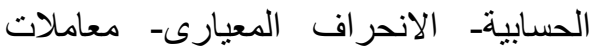
الارتباط البسيط-اختبار "F"- تحليل الانحدار

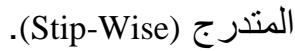

\section{النتائج ومناقشتها}

أولاً: وصف عينة الدراسة

أوضحت البيانات أن المبحوثين بعينة

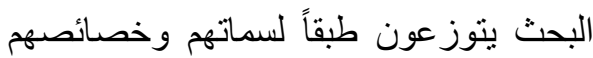

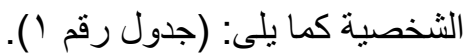

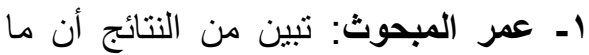

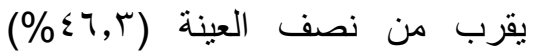

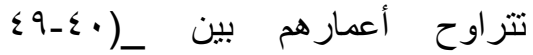
درجة)، وأن حوالى ما يقرب من ثلث اعثل

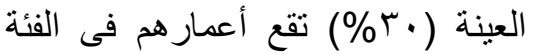
أقل من • أعنة سنة، وأن أقل قليلاً من ثلث

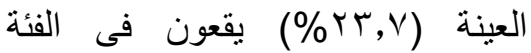
العمرية .0 سنة فأكثر ، و هذا يثير إلى فئى

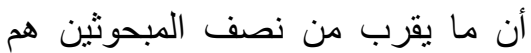

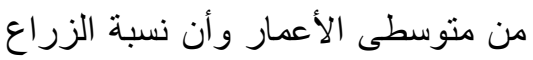

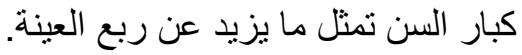

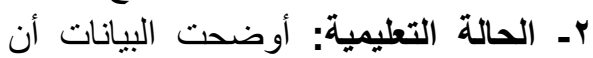
نحو نصف العينة من المبحوثين العين

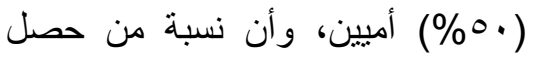

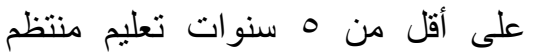

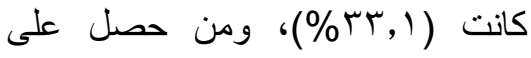

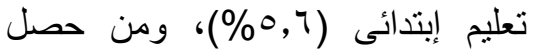

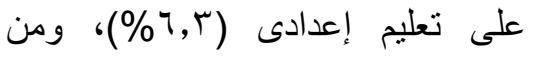

ح) الاتجاه نحو المستحثثات الزراعية

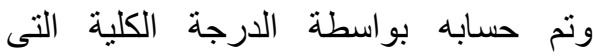
يحصل عليها المبحوث من خلال الاستجابات

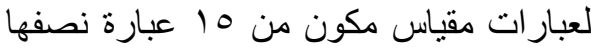

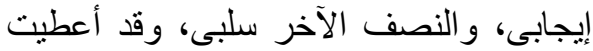

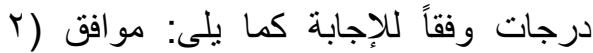

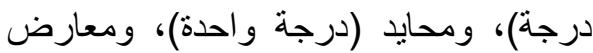

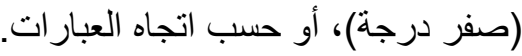
ط) الاتصال بوكلاء التغيير: ونم التهاه حسابه بواسطة الدرجة الكلية التى يحصل علئه التهاء المبحوث دـن خلال استجاباته، وقد أعطيت لأني

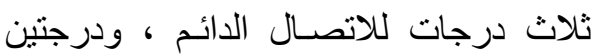

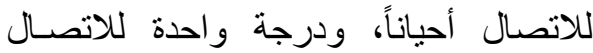

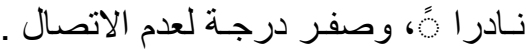

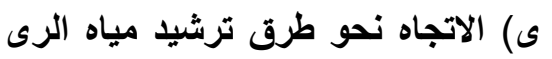

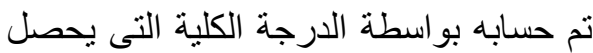
عليها المبحوث من خلال استجاباته لعبارات

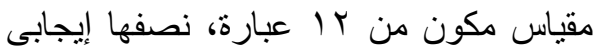

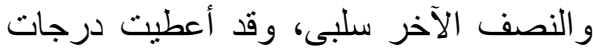

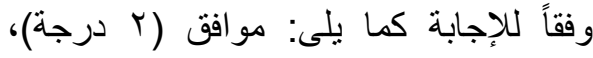

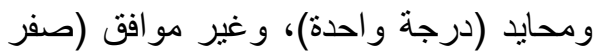
درجة)، أو حسب اتجاه العبارة. ك) مشاركة المبحوثين فى إدارة وصيانة التهاه شبكات الرى: تم حسابه بواسطة الدرجة الرة وصنانة الكلية التى يحصل عليها المبحوث من خلال استجاباته لعبار ات المقياس و المكون من 1 التهن

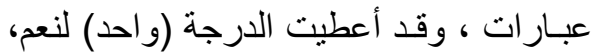
و الارجة (صفر) لا أشارك. ثامناً: أدوات التحليل الإحصائى تم الاستعانة بالحاسب الآلى فى تحليل

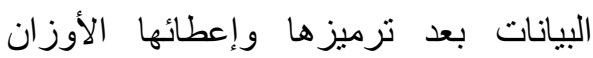


هـ التعرض لوسائل الاتصال الجماهيرية:

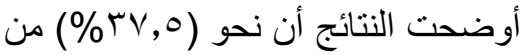

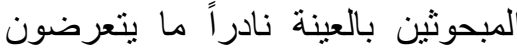

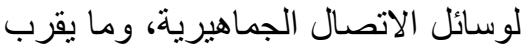

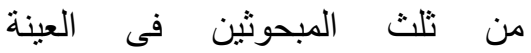

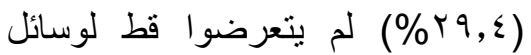

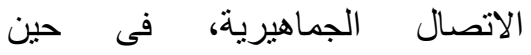

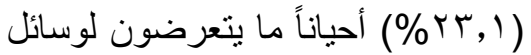

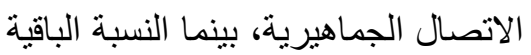

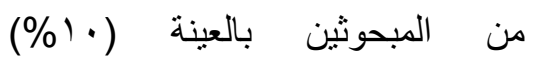
يتعرضون بصفة دائمة لوسائل الاتصال الجماهيرية، و هذا ما يشير إلى أن أكثر لئر

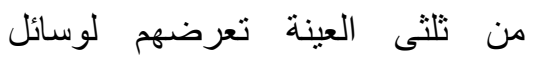
الاتصال الجماهيرية كان ضعيفاً، وهذان لونة ما بفسر طبيعة منطقة البحث وبته وبعدها وهان عن مر اكز الاتصال الجماهيرية. צ- مدة العمل الزراعى: أوضحت البيانات أن أن البهات ما يقرب من ثناث أربات أرباع المبحوثين

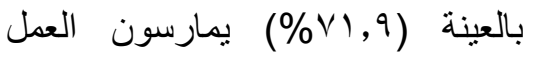

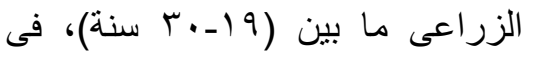

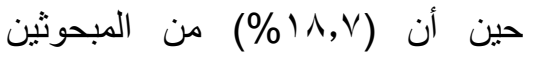
بالعينة بمارسون العمل الزراعى (أكثر

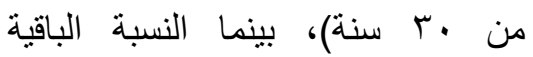

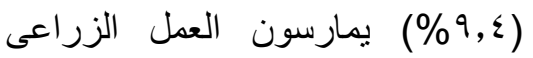

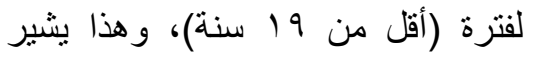

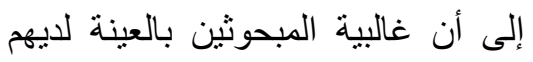
فكرة جيدة عن الزراعة ولكن قد تكون

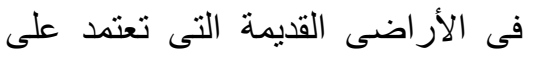

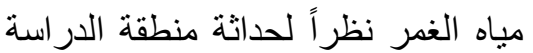
التى انتقلوا إليها.

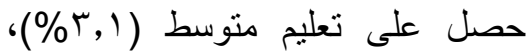
وأن نسبة من حصل على على تعليم عالى (ألى

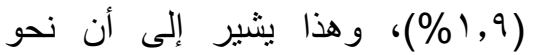

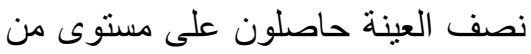

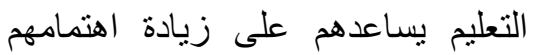

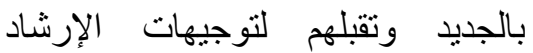

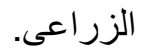
r- الانفتاح الحضارى: أوضحت البيانات أن

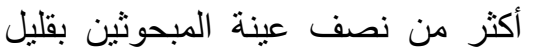

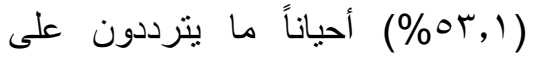

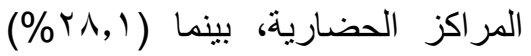

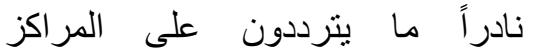

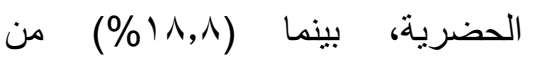

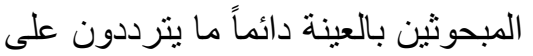

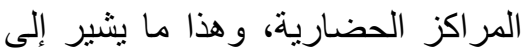
أن ما يقرب من ثلاث أرباع المبحوثين

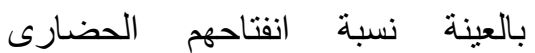
منخفض نسبياً، وهذا قد يؤثر بشكل مباشر على معارفهم ومهار اتهم فيى هذا بذان

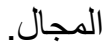
ع- المشاركـة في المنظمـات المحليـة: أوضحت النتائج أن غالبية المبحوثين

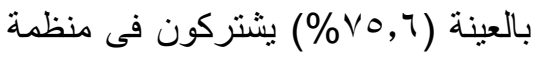

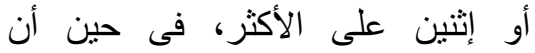

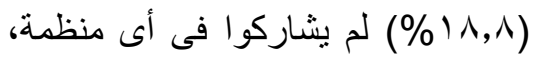

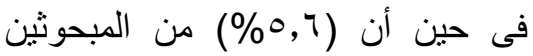

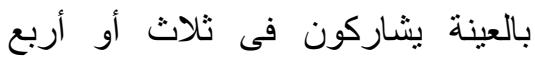

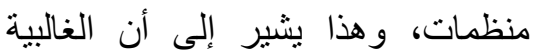

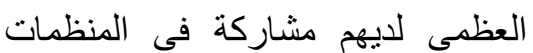
العادية بقرى الدر اسة. 
دائماً يتصلون بوكلاء التغيير خاصة

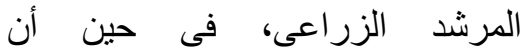

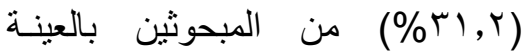
أحيانـاً ما يتصلون بوكلاء التغيير، بينما (\%/^,〉)

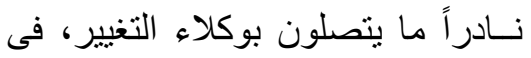

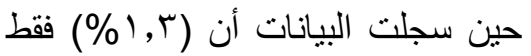

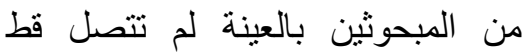
بوكلاء التغيير، وهذا يفسر بالعينة أن الخدمة

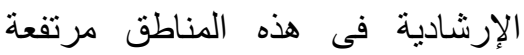

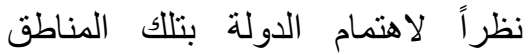

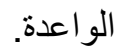
1- الاتجـاه نحو طرق ترشيد الرى الرى الرقان

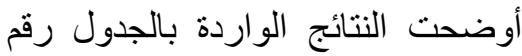

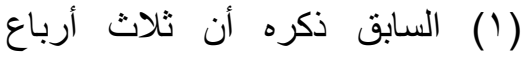

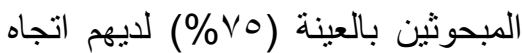

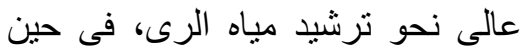
أن (1/,1\%) من المبحوثين بالعينة

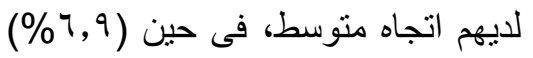
من المبحوثين بالعينة لديهم اتجاه ضعيف، وهذا ما قد يفسر الهنمام

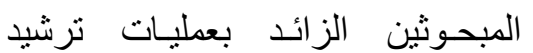

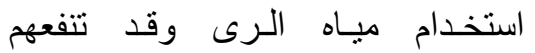
المعلومات الفنية فى ذلك. 1 ا - المشاركة فى إدارة وصيانة شبكات

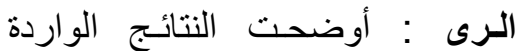

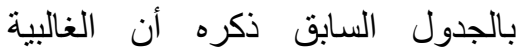

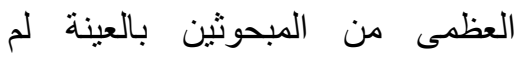

V- الرضا عن العمل الزراعى: أوضحت

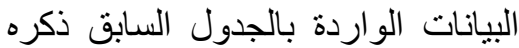
أن نصف المبحوثين بالعينة (•0\%)

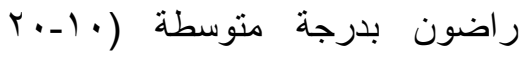

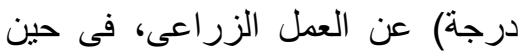

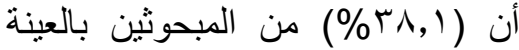

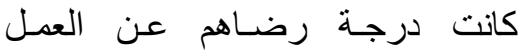

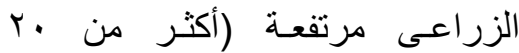
درجة)، بينما النسبة الباقية (1, (1) (1)

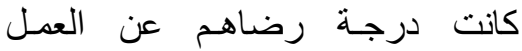

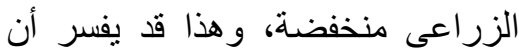

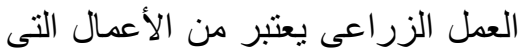
تحتاج إلى إمكانيات قد لا تكون منو الاعمال 1- الاتجاه نحو المستحدثات الزراعية

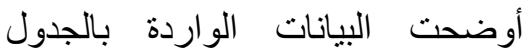

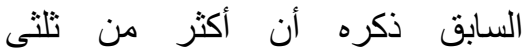

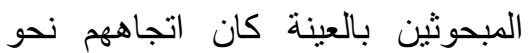

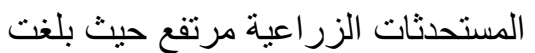

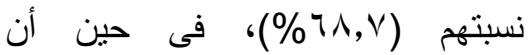
(\%/^,^)

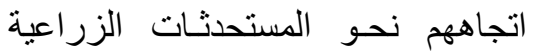

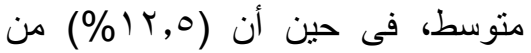

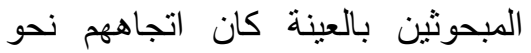
المستحدثات الزر اعية منخفض. 9ـ الاتصال بوكلاء التغيير: أوضحت التهن النتائج

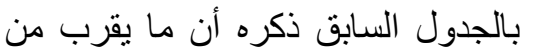

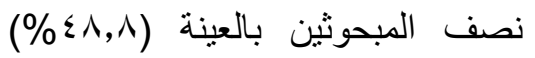


جدول رقم ا : توزيع المبحوثين وفقاً للمستوى السائدلبعض المتغيرات الثخصية و الموقفية المستقلة

\begin{tabular}{|c|c|c|c|c|c|c|c|}
\hline$\%$ & 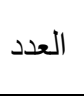 & فئات المتغير ات & الإنحر اف المعيارى & الحستوسط الحسب & قأكبر & ق أقل & المتغير ات \\
\hline r. & $\varepsilon \wedge$ & (أقل من • ع) سنة & $r \varepsilon, Y V$ & $\varepsilon \varepsilon, \cdot r$ & 09 & r. & - \\
\hline$\varepsilon \tau, r$ & $\vee \varepsilon$ & 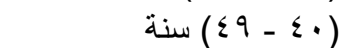 & & & & & المبحوث \\
\hline$r$ r,v & بᄉ & ( م سنة فأكثر ) & & & & & \\
\hline $1 \ldots$ & 17. & المجموع & & & & & \\
\hline $0 \cdot, \cdot$ & $\Lambda$. & أمسـى & $|\varepsilon, v|$ & ס ס,TM & 17 & صفر & بـ الحالة \\
\hline l l & or & منتظم من سنوات تعليم & & & & & التعليمية \\
\hline 0,7 & 9 & حاصل على الابتدائية & & & & & \\
\hline 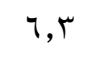 & 1. & حاصل على الإعدادية & & & & & \\
\hline r,l & ○ & حاصل على مؤهل متوسط & & & & & \\
\hline 1,9 & r & حاصل على مؤهل جامعى & & & & & \\
\hline $1 \ldots$ & 17. & المجموع & & & & & \\
\hline$r \wedge, 1$ & $\leqslant 0$ & نادراً & $\cdot, 7 V$ & $1, \leqslant 1$ & $r$ & صفر & " الانفتاح \\
\hline or, 1 & 10 & أحياناً & & & & & الحضـارى \\
\hline$\curlywedge \wedge, \wedge$ & ro & 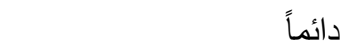 & & & & & \\
\hline $1 \ldots$ & 17. & المجموع & & & & & \\
\hline $1 \wedge, \wedge$ & $r$. & لم يشارك قط & $\cdot, \leqslant \wedge$ & $1, \Gamma \varepsilon$ & $\varepsilon$ & صفر & ع ــ المشاركة \\
\hline Vo, 7 & $|r|$ & مشارك في (Y-1) منظمة & & & & & فى \\
\hline 0,7 & 9 & مشارك فى (س-ع) منظمة & & & & & المنظمات \\
\hline & & & & & & & المحلية \\
\hline $1 \ldots$ & 17. & المجموع & & & & & \\
\hline$r q, \varepsilon$ & $\varepsilon V$ & لم يتعرض قط & $\cdot, 90$ & 1, & r & صفر & هـ التعرض \\
\hline$r v, 0$ & 7. & ن ن نادراً & & & & & ل ل ل وسائل \\
\hline rr, & rv & أحياناً & & & & & الاتصـال \\
\hline $1 \cdot, \cdot$ & 17 & دائمــاً & & & & & الجماهيرية \\
\hline $1 \ldots$ & 17. & المجموع & & & & & \\
\hline $9, \varepsilon$ & 10 & (أقل من 9 1) سنة & $7, \cdot$ & Yo,OV & $\sum r$ & V & 7- مدة العمل \\
\hline$\vee 1,9$ & 110 & ) - (19) سنة & & & & & الزر اعى \\
\hline $1 \wedge, \vee$ & $r$. & (أكثر من · ب) سنة & & & & & \\
\hline $1 \cdots$ & 17. & المجموع & & & & & \\
\hline
\end{tabular}

Arab Univ. J. Agric. Sci., 14(1), 2006 
تابـع جدول رقم ا: توزيع المبحوثين وفقاً للمستوى السائد لبعض المتغيرات الثخصية والموقفية المستقلة

\begin{tabular}{|c|c|c|c|c|c|c|}
\hline$\%$ & 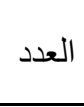 & فئات المنغير ات & الإنحر اف المعيارى & الحسابى & قأقل قأكبر & المتغير ات \\
\hline & - & غير راضى (صفر درجة) & $7, \leqslant 0$ & $1 V, 71$ & صفر . & V- الرضا عن \\
\hline 11,9 & 19 & ر اضى بدرجة منخفضة & & & & العمل الزراعى \\
\hline $0 \cdot, \cdot$ & $\wedge$. & ر ( • • • ب درجى بدرجة متوسطة) & & & & \\
\hline rی, & 71 & 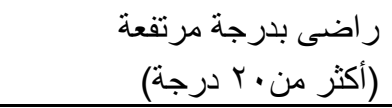 & & & & \\
\hline $1 \ldots$ & 17. & المجموع & & & & \\
\hline IY,O & 1. & منخفض (أقل من · ا درجة) & $V, \cdot \varepsilon$ & r.,Tr & صفر . ب & 1 - الاتجاه نحو \\
\hline $1 \wedge, \wedge$ & $r \cdot$ & متوسط ( • - • ب درجة) & & & & المستحدثات \\
\hline $7 \wedge, \mathrm{V}$ & 11. & مرتفع (أكثر من · r درجة) & & & & الزر اعية \\
\hline $1 \cdots$ & 17. & المجموع & & & & \\
\hline $1, r$ & $r$ & لم يتصل قط(أقل من () درجة & $\cdot, \wedge$ & $r, V V$ & صفر r & 9 - الاتصال \\
\hline $1 \wedge, \mathrm{V}$ & $r$. & نادراً ما يتصل( (- (درجة & & & & بو كلاء التغيير \\
\hline r l, & 0 & أحياناً ما يتصل (Y-Y) درجة & & & & \\
\hline$\varepsilon \wedge, \wedge$ & $\vee \wedge$ & دائماً ما يتصل(r درجة فأكثر) & & & & \\
\hline $1 \cdots$ & 17. & المجموع & & & & \\
\hline 7,9 & 11 & منخفض (أقل من ^ درجة) & $\varepsilon, \vee\urcorner$ & $1 V, \leqslant 0$ & صفر ع & · ـ الاتجاه نحو \\
\hline $1 \wedge, 1$ & rq & متوسط (^- 71 درجة) & & & & طرق ترشيد \\
\hline vo, & 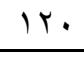 & عالى (7 ا درجة فأكثر) & & & & الرى \\
\hline $1 \cdots$ & 17. & المجموع & & & & \\
\hline iv,o & $1 \leqslant$. & لا يشارك (أقل من درجة) & $1, r r$ & $\cdot, \wedge 9$ & صفر 1 & 11 \\
\hline $10, r$ & 1. & منخفضة ( (1-r درجة) & & & & المبحوثين \\
\hline r,l & 0 & عالية (أكثر من ه درجات) & & & & فى إدارة وصيانة \\
\hline & & & & & & شبكات ونظم الرى \\
\hline $1 \ldots$ & 17. & المجموع & & & & \\
\hline
\end{tabular}

المصدر: عينة الدر اسة الميدانية.

Arab Univ. J. Agric. Sci., 14(1), 2006 
التتفيذية للتوصيات الخاصة بترشيد مياه

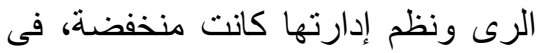

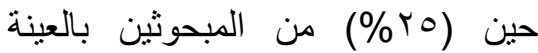

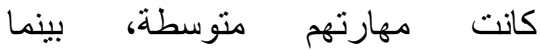

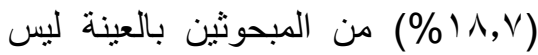

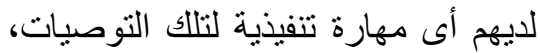
بينما (\%)

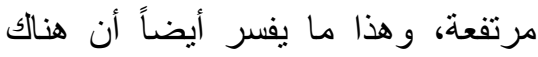

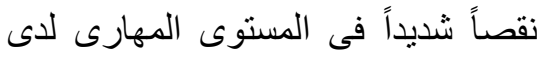

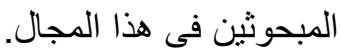

ثالثاً: تحديد النقص فى درجـة معارف

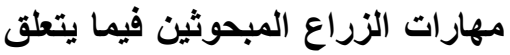

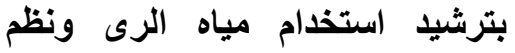

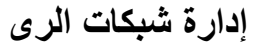

فيما يتعلق بالهدف الثانى الذى يسعى إلى

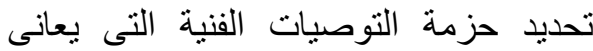
الزراع من مشكلة نقص الإلمام بها وتتفيذها

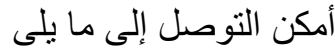
أ- النقص المعرفى إنى أوضحت النتائج الواردة بالجدول رقم

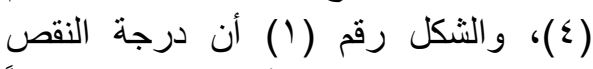
المعرفى لدى الزراع أمكن ترنيبها ترنياً

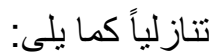

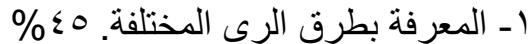
r- المعرفـة بكيفية استخدام شبكات الرى الرى \% \% الحديثة. بـ المعرفـة بعدد مرات رى المحاصيل $\%$ Y个 المختلفة. ع- المعرفـة بطرق إدارة نظم الرى $\% r$.
يشاركوا قط فى إدارة وصيانة شبكات

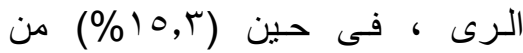
المبحوثين بالعينة كانت مشاركتهم

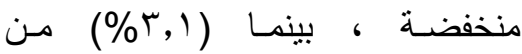
المبحوثين بالعينة كانت مشاركته عالية

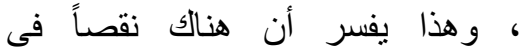
المستوى المهارى والمعرفى فى هذا فئ فئ

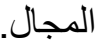

ثانياً: المستوى المعرفى والتنفيذى للزراع

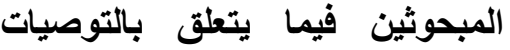
القنية الخاصة بترشيد استخدام مياه الرى ونظم إدارتها 1- المستوى المعرفى: أوضحت النتائج

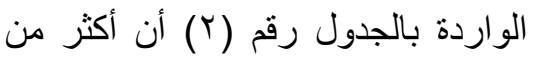

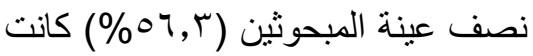

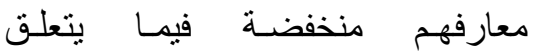
بالتوصيات الفنية الخاصة بترشيد استخدام مياه الرى ونظم إدارتها، فى النى

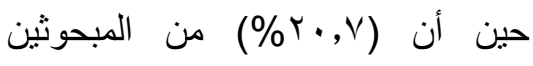
بالعينة ليس لايهم معرفـة عن تلإن

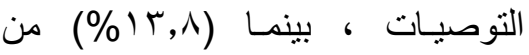
المبحوثين بالعينة كانت معارفهم فى هذا

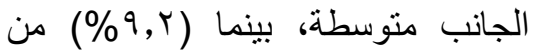

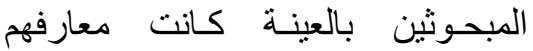
مرتفعة ، و هذا يشير إلى أن هناك نقان فئساً

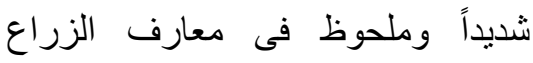
المبحوثين فى ذلك المجال. r- المستوى التنفيذى : أوضحت فئ النتائج

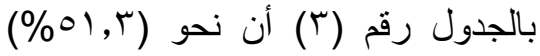
من المبحوثين بالعينة كانت مهارتهم 
جدول رقم ب: توزيع المبحوثين وفقاً للمستوى المعرفى الخـاص بترشيد استخدام مياه الرى ونظم إدارنها

\begin{tabular}{|c|c|c|}
\hline \multicolumn{2}{|c|}{ المكون المعرفى } & \multirow{2}{*}{ البيــــان } \\
\hline$\%$ & 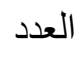 & \\
\hline$r \cdot, V$ & זr & لا يعرف (صفر درجة) \\
\hline 07, & 9. & منخفض (1 - 9 درجة) \\
\hline 1 ו, & r & منوسط (·• (- 9 ( درجة) \\
\hline $9, r$ & 10 & مرتفع ( • r درجة فأكثر) \\
\hline $1 \ldots$ & 17. & المجموع \\
\hline
\end{tabular}

المصدر: عينة الدر اسة الميدانية.

جدول رقم ب: توزيـع المبحوثين وفقاً للمستوى التنفيذى الخاص بترشيد استخدام مياه الرى ونظم إدن ونئ

\begin{tabular}{|c|c|c|}
\hline \multicolumn{2}{|c|}{ المستوى التنفيذى } & \multirow{2}{*}{ البيـــان } \\
\hline$\%$ & 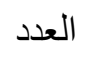 & \\
\hline $1 \wedge, V$ & $r$. & لا بنفذ (صفر درجة) \\
\hline $01, r$ & Ar & منخفض (1 - ^ درجة) \\
\hline ro,. & $\varepsilon$. & متوسط (9 - V ا درجة) \\
\hline $0,$. & $\Lambda$ & مرتفع (^ا درجة فأكثر) \\
\hline $1 \ldots$, & 19. & المجموع \\
\hline
\end{tabular}

المصدر: عينة الدر اسة الميدانية. 
$1 \mathrm{~V}$ برنامج إرشادى لإستخدام مياه الرى بدرب الأربعين

جدول رقم §: توزيع المبحوثين وفقاً لمتوسط درجة المعرفة فيما يتعلق بمجموعات التوصيات الفنية لترشيد استخدام مياه الرى ونظئ وفئ إدارتها

\begin{tabular}{|c|c|c|c|c|c|}
\hline $\begin{array}{c}\% \\
\text { المعرفى للنقص }\end{array}$ & \% لمتوسط المعرفة & الأهمبة & متوسط & لترشيد استخدام مياه الرى التونيات الفنية & r \\
\hline $1 \wedge, \varepsilon$ & 11,7 & 7 & $\varepsilon, 9$ & إكساب الحائزين المعرفة فى كيفية تطهير & 1 \\
\hline r., & $\Lambda \cdot, \cdot$ & V & 0,7 & أكناء الرى الحائزين المعرفة بنظام المناوبات & $r$ \\
\hline$\leqslant 0,$. & 00, . & $\varepsilon$ & $r, r$ & المختلفة الحسئزين المعرفـة بطـرق الرى & r \\
\hline ro,. & Vo, & r & 1,0 & الركساب الحائزين المعرفـة بعدد مرات & $\varepsilon$ \\
\hline . & $\neg \Lambda$, & 0 & r, $\Sigma$ & شبكات الرى الحساب الحئزين المعرفة بكيفيـة استخدام & 0 \\
\hline IV,. & ז, & r & $r, 0$ & آلات الرساب الحائزين المعرفـة بطرق صيانة & 7 \\
\hline r., & $\Lambda \cdot, \cdot$ & 1 & $\cdot, \wedge$ & إكساب الحائزين المعرفـة بطرق إدارة & $V$ \\
\hline
\end{tabular}

المصدر: عينة الدر اسة الميدانية.

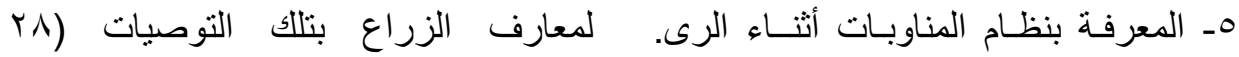

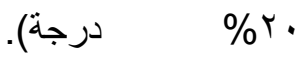

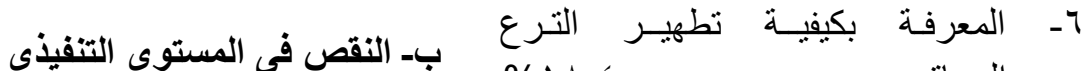

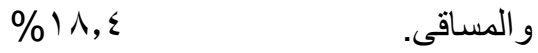

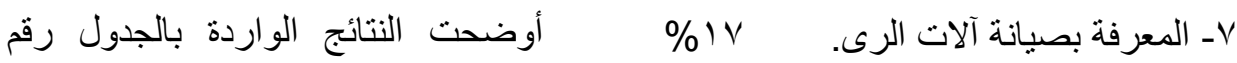

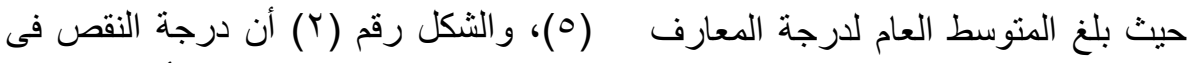

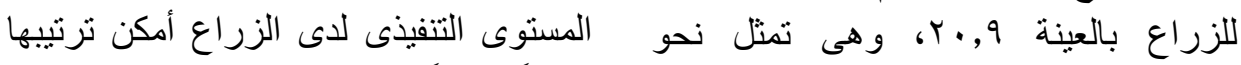

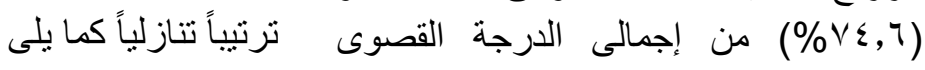




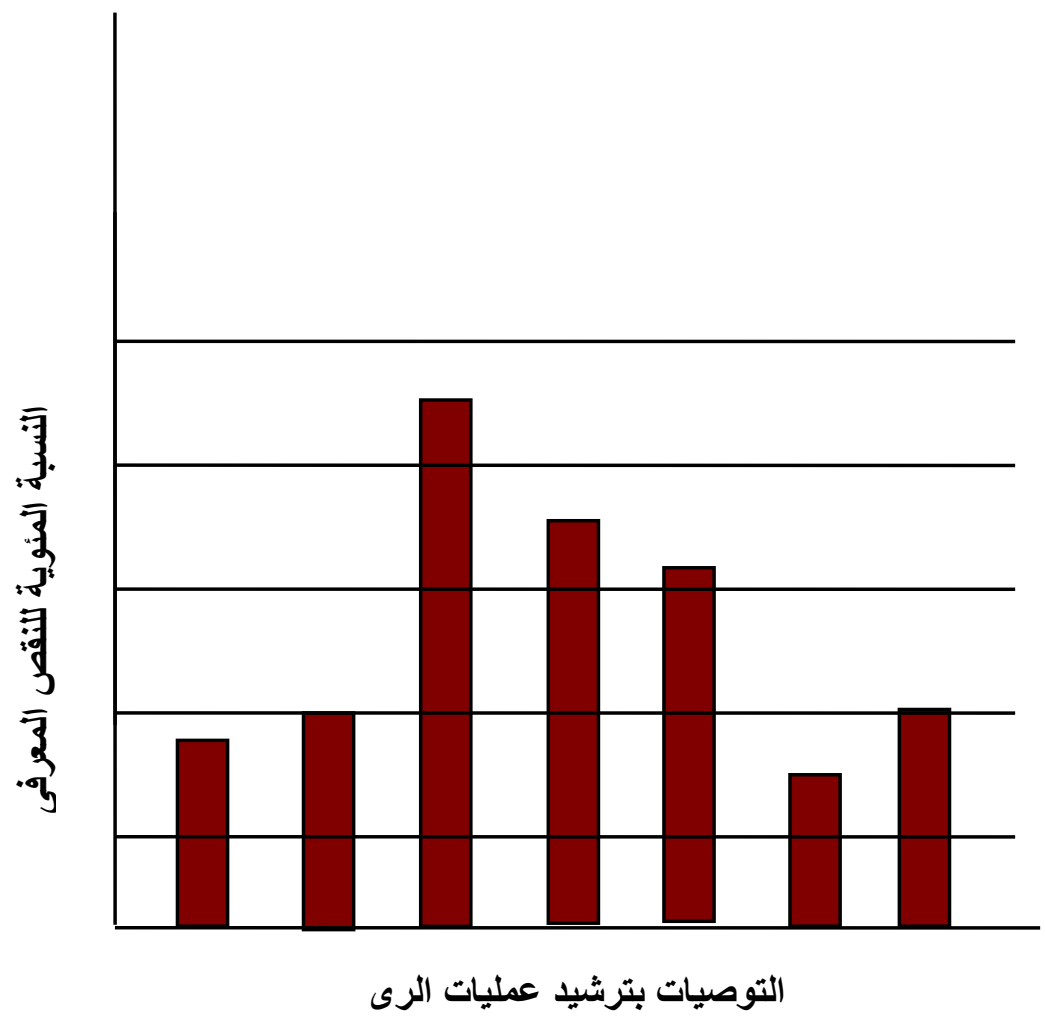

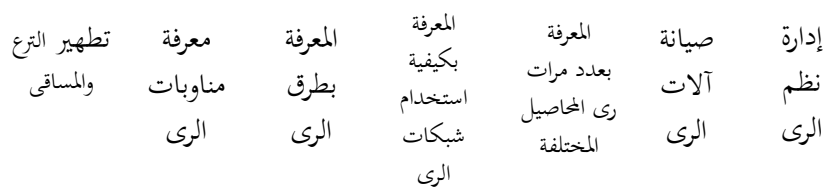

شكل رقم ا: النص المعرفى للزراع المبحوثين فى عمليات نرشيد و إدارة نظم الرى 
جدول رقم ه : نوزيع المبحوثين وفقاً لهنوسط درجـة التنفيذ لمجموعات التوصيات الفنية لترشيد استخدام مياه الرى ونظم ونظم إدارتها

\begin{tabular}{|c|c|c|c|c|c|}
\hline فى المستوى للنقص التنفيذى & \% لمتوسط & الأهمية & متوسط & 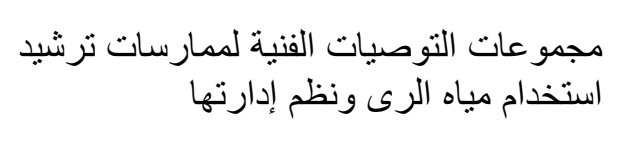 & \\
\hline $00, \wedge$ & $\varepsilon \varepsilon, Y$ & V & r, & التصـرف السلبم فى حالة تلـوث الترع & 1 \\
\hline r, & $\varepsilon r, V$ & $\Lambda$ & $r, 0$ & التصى لنه السليم فى حالة عدم وصـول مياه & $r$ \\
\hline$T V, 0$ & ס, & $\varepsilon$ & r, & التصائزين & r \\
\hline$v_{\cdot}, \cdot$ & •, , . & r & $\cdot, 9$ & الرى التصرف السليـم فى حالـة إنسداد شبكات & $\varepsilon$ \\
\hline$\neg \varepsilon, V$ & 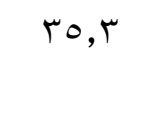 & 7 & $r, 1 r$ & شبكات الرى التصرف السليم فى حالة وجـود كسر فى & 0 \\
\hline$V \cdot, \cdot$ & 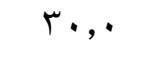 & 0 & 1,0 & التصرف السليم لصيانة آلات الرى & 7 \\
\hline $0 .,$. & $0 .,$. & 1 & $\cdot, 0$ & قبل التصرفئزين السليم فى ترشيد ميـاه الـرى من & V \\
\hline $7 \cdot, \cdot$ & $\varepsilon \cdot, \cdot$ & r & $\cdot, \wedge$ & التصرى الحقلى السليم فى الإدارة السليمة لنظم & $\wedge$ \\
\hline
\end{tabular}

المصدر: عينة الدراسة الميدانية.

1- التصرف السليم فى حالة انسداد شبكات 0ـ التصـرف السليم فى حالة إدارة نظم

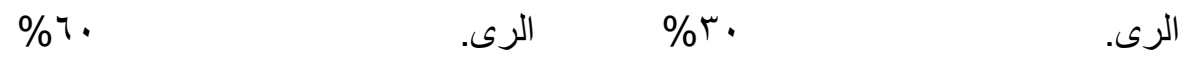

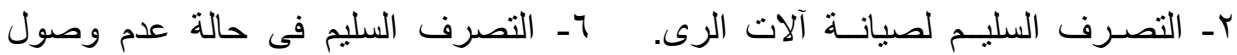

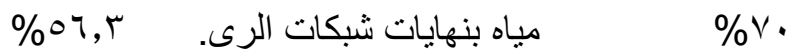

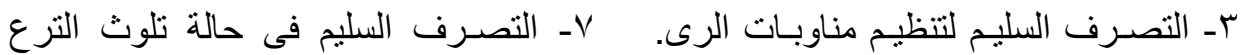

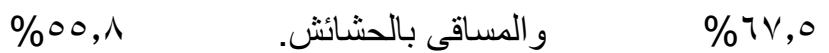

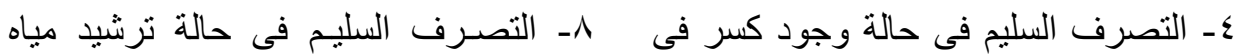

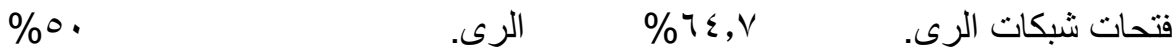




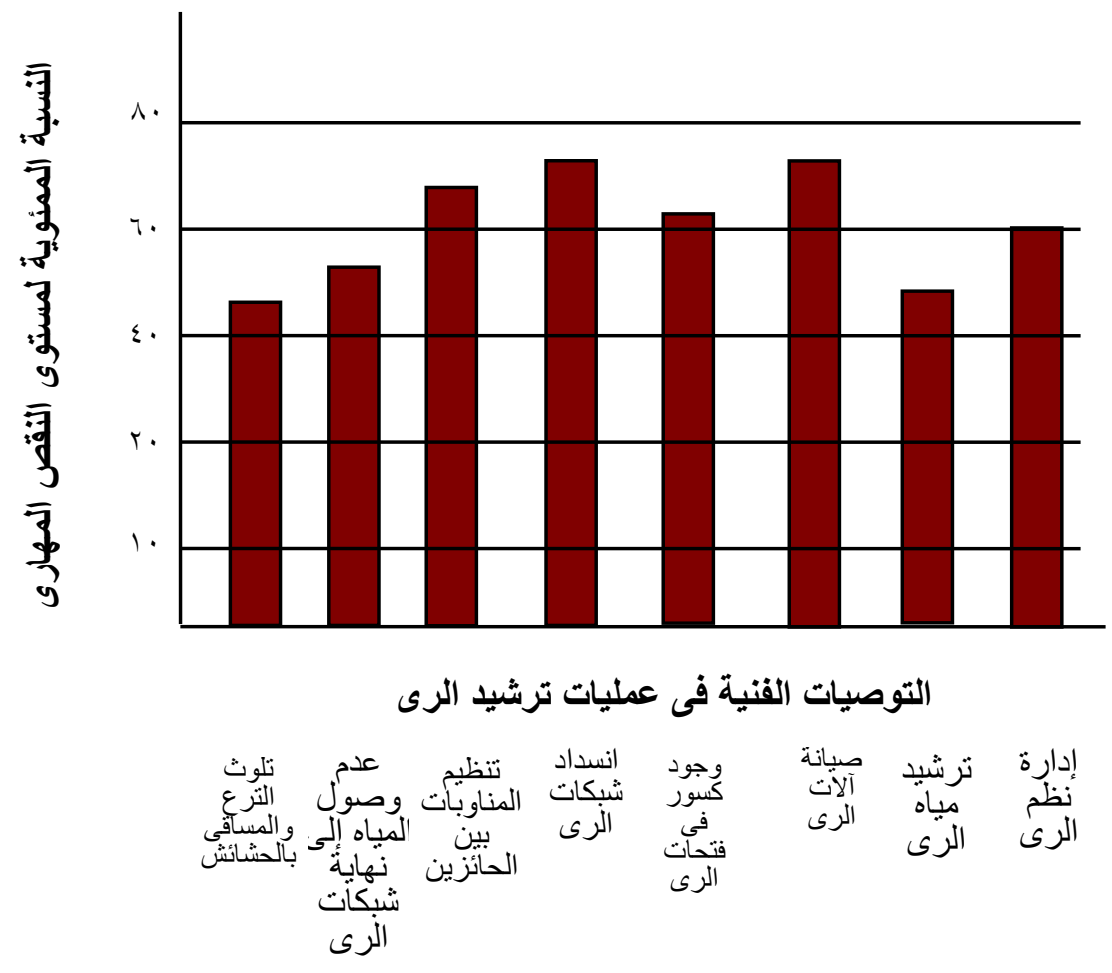

شكل رقم ب: النقص فى المستوى المهارى للزراع المبحوثين فى عمليات ترشيد وإدارة نظم 
rI برنامج إرشادى لإستخدام مياه الرى بدرب الأربعين

جدول رقم 7: قيم معاملات الارتباط البسيط بين المتغيرات الثخصية والمعرفية للمبحوثين

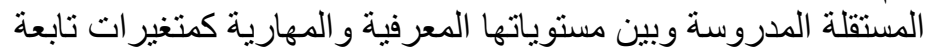

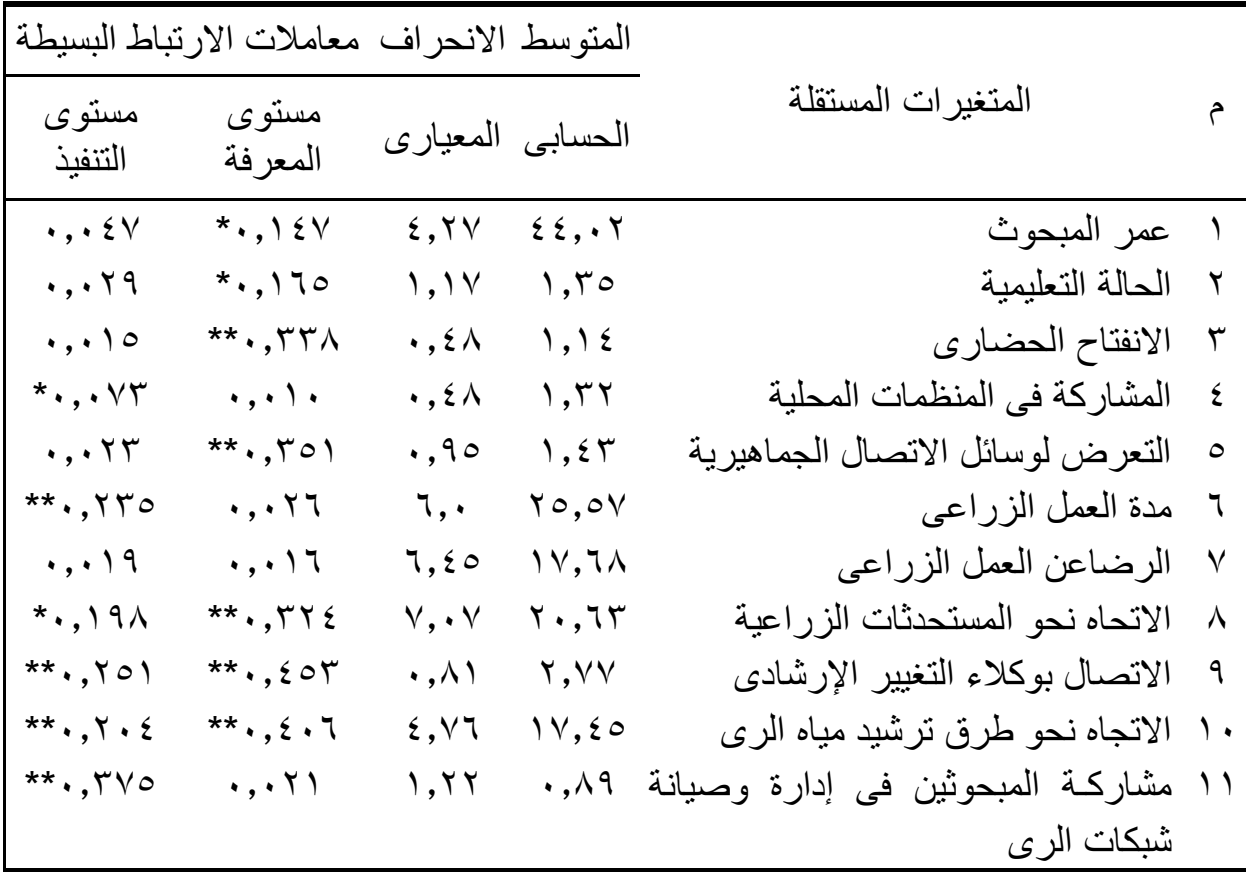

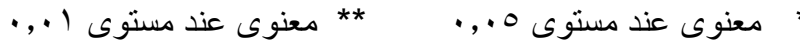

المصدر: عينة الدر اسة الميدانية.

حيث بلغ المتوسط العام لدرجة التنفيذ إلـ المستوى المعرفى

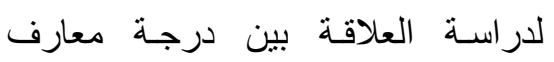

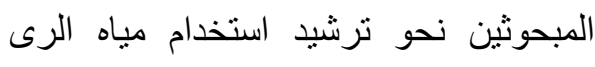

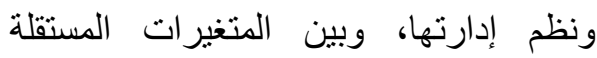

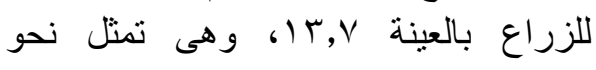

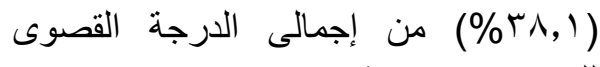
للتنفيذ. ( (ب درجة). المدروسة فقد تم صياغة الفرض الإحصائى

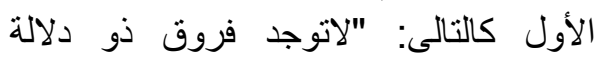

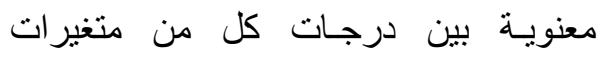

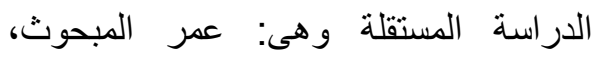

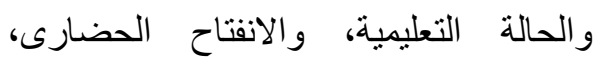

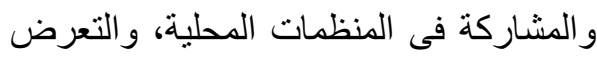

رابعاً: علاقة بعض المتغيرات الثخصية

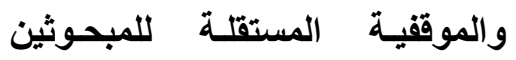
بمستوى معارفهم ومهار ماتهم التنفيذية لممارسات ترشيد استخدام مياه الرى ونظم إدارتها 
إدارتها، وكل من: المشاركة فى المنظمات

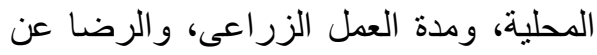

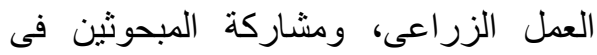

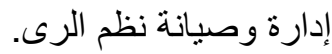

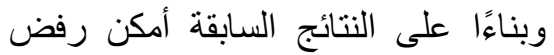

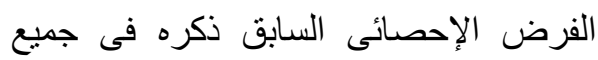

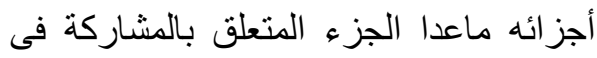

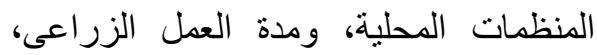

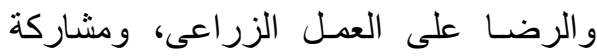
المبحوثين فى إدارة وصيانة نظم الرىى. لرئ

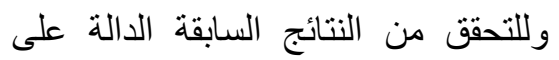
وجود علاقة بين درجة ومعارف المبحوثين

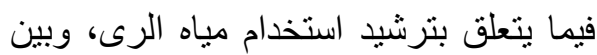

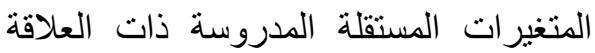

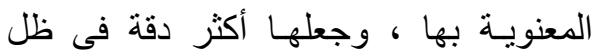

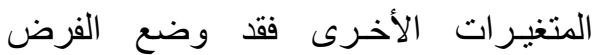
الإحصائى الثنانى كالتالى: "لا يسهر كل متغير الأنير

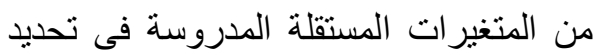

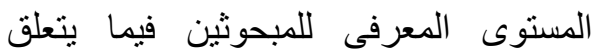
بالتوصيات الفنية فى مجال ترشيد استخدام مياه الرى ونظم إدارتها لتفسير التباين الكلى تلى التيد لارجة هذه المعارف". ولاختبار صحة هذا الفرض الإحصائى لئى

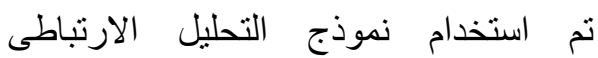
و الانحدارى المتدرج الصاعد وذلك بعد التأكد

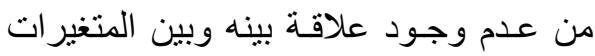
بمصفوفة الارتباط، وتبين من النتائج الواردة

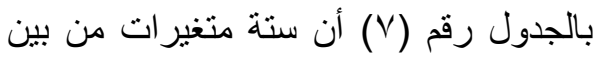

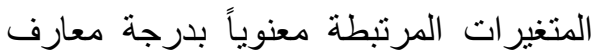

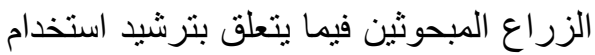

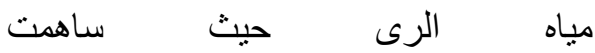

لوسائل الاتصال الجماهيرية، ومدة العمل

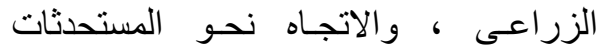
الزراعيـة ، و والاتصـال بوكـلاء التغيير

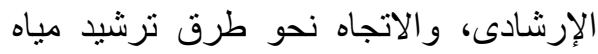

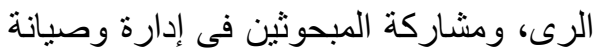

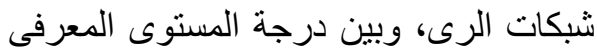
للتوصيات الفنية المتعلقة بترشيد استخدام مياه الرى ونظم إدارتها".

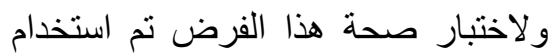

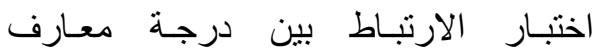

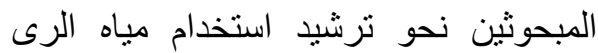

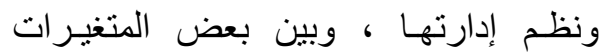
المستقلة المدروسة. وأوضحت النتائج الواردة بالجدول رقم

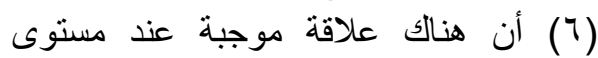

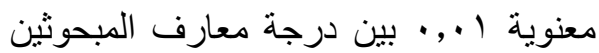
نحو ترشيد استخدام مياه الرى ونظم إدارتها،

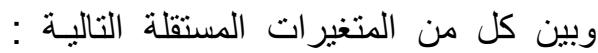

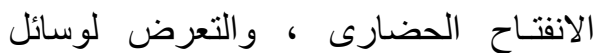

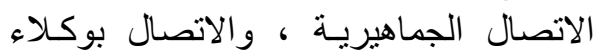

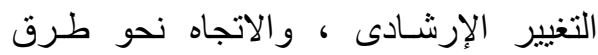
ترشيد مياه الرى ، و الاتجاه نحو المستحدثات التحاه

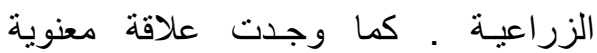

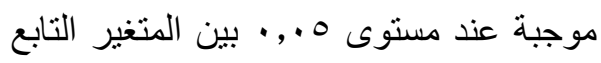

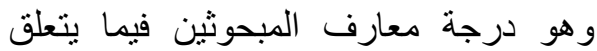

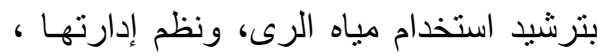

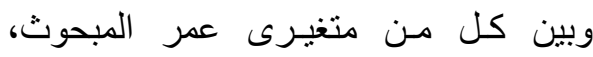
و الحالة التعليمية.

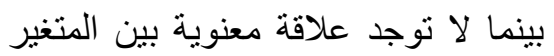

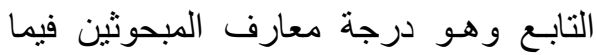
يتعلق بترشيد استخدام مياه الرى ورن ونظم 
جدول رقم У: التحليل الارتباطى والانحدارى المتعدد لعلاقة مستوى التغبير فى المستوى المعرفى وبعض متغير ات الدر اسة المستقلة

\begin{tabular}{|c|c|c|c|c|c|}
\hline 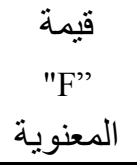 & الانحدار معامل & 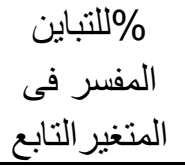 & الارنباط المتعدد & المتغير الداخل فى التحليل & الخطو ات \\
\hline *., , ro &., $.9 \leq$ & $0, Y 07$ & $\cdot, .91$ & الإرشادى الإل بوكلاء التغييـر & الأولى \\
\hline$* ., .17$ & $\cdot, 1 \leq \wedge$ & $\varepsilon, Y \leq \varepsilon$ & $\cdot, \cdot V r$ & الاتجـاه نحو المستحدثـات & الثانية \\
\hline *., , rr & $r, Y \backslash Y$ & $r, Y, \varepsilon$ & $\cdot, \cdot 7 \leq$ & 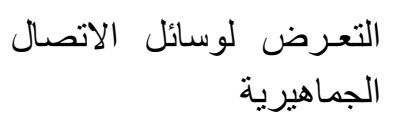 & الثالثة \\
\hline *., , rv & $1,9 \vee V$ & $r, l \leq$. &., .01 & الانفتاح الحضارى & الر ابعة \\
\hline$* ., .7 V$ & • & $1, .9 V$ & $\cdot, \cdot \leq V$ & الحالة التعليمية & الخامسة \\
\hline$* ., .70$ & $\cdot, \mid \vee \wedge$ & $1, .71$ & $\cdot, \cdot \leq 0$ & عمر المبحوث & السادسة \\
\hline
\end{tabular}

بأن المتغير ات المستقلة السابقة الذكر هى من

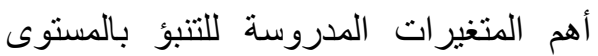

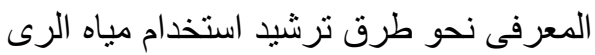

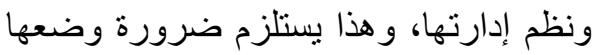

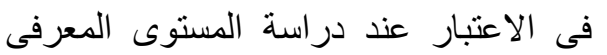
للزراع فيما يتعلق بترشيد استخدام مياه الرى دئد ونظم إدارتها.

ץ- المستوى التنفيذى (المهارى)

بدراسـة العلاقة بين درجة المستوى المئ التنفيذى (المهارى) للمبحوثين نحو ترشيد استخدام مياه الرى ونظم إدارتها، وبين لترونين
مجتمعة فى التنبؤ المعرفى بنسبة (V)

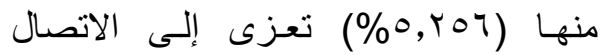

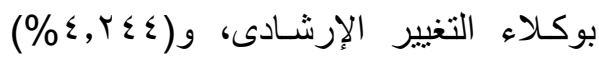

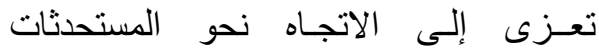

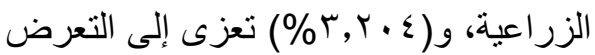

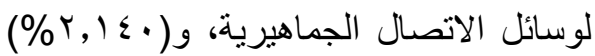

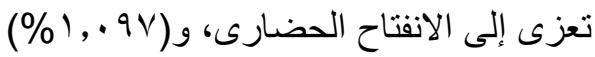

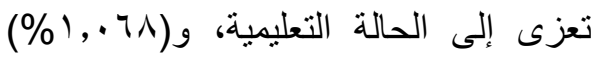
تعزى إلى عمر المبحوث.

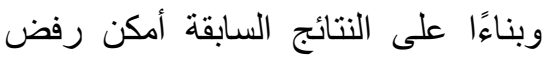
الفرض الإحصائى السابق ذ ذكره، وقبول

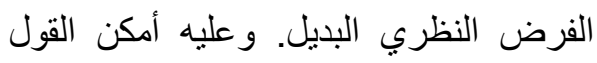


كما وجدت علاقة معنوية موجبة عند

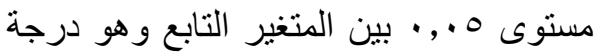
المستوى التنفيذى المهارى للمبحوثين نحو النئني

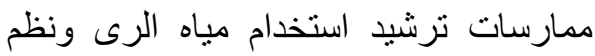
إدارتها، وبين كل من المتغيرات المستقلة المنات

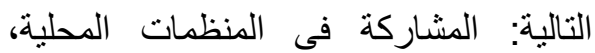

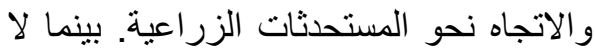

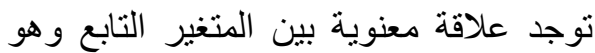

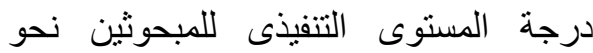

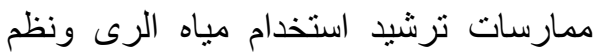
إدارتها، وبين كل من المتغيرات المستقلة الرئة

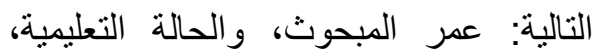
والانفتاح الحضارى، و والتعرض ولئل لوسائل الاتصال الجماهيرية، و الرضا ولفيا عن العمل لوضلت

$$
\text { الزر اعى. - الاتصال. }
$$

وبناءً على النتائج السابق ذكرها أمكن

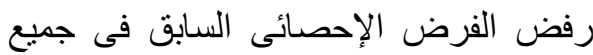

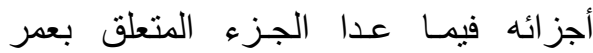

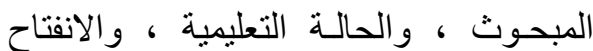

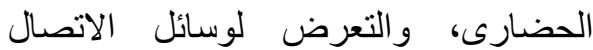

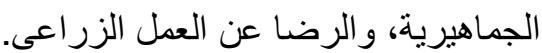

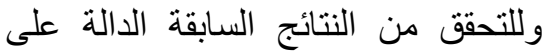

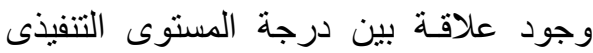

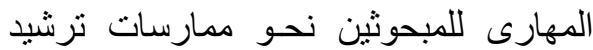

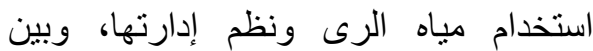
المتغيرات المستقلة ذات العلاقة المعنوية بها، وجعلها أكثر دقة فى ظل المتغيرات الأخرى.

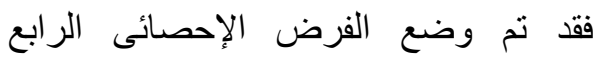
كالتالى: "لا يسه كل متغير من المن المتغير ات

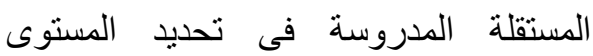

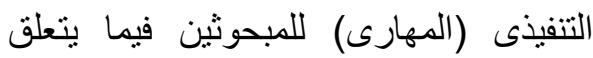

المتغيرات المستقلة المدروسة فقد تم صياغة الفرض الإحصائى الثانى كالتالى: "لا نوجد فروق ذو دلالة معنوية بين درجة كل من الاحني

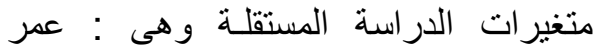

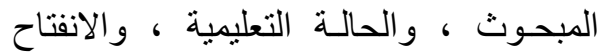

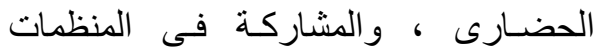

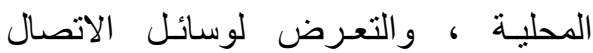
الجماهيرية ، ومدة العمل الزر اعى، ولاعن والاتجاه

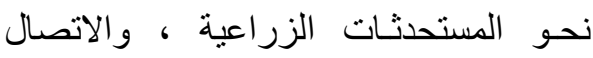

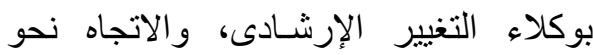
طرق ترشيد مياه الرى، ومشاركة المبحوثين

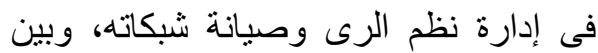
درجة المستوى التنفيذى المهارى للتوصيات الفنية المتعلقة بممارسات ترشيد استخدام مياه الرى ونظم إدارتها". ولاختبار صحة هذا الفرض التراط التخدم اختبار

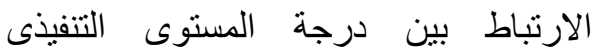
المهارى للمبحوثين نحو ممارسات ترشيد استخدام مياه الرى ونظة إدارتها، وبنين المتغير ات المستقلة المدروسة.

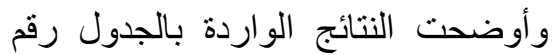

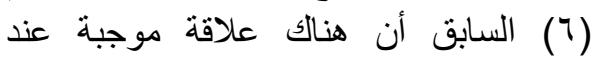
مستوى معنوية ا.,, ب. بين درجة المستوى التنفيذى المهارى للمبحوثين نحو ممارسات ترشيد استخدام مياه الرى ونظم إدارتها، وبين كل من المتغيرات التالية: مدة العمل التطاه

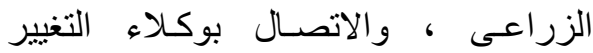

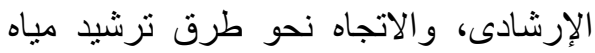

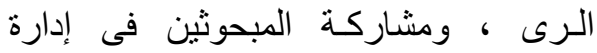

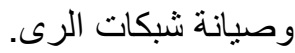


ro

برنامج إرشادى لإستخدام مياه الرى بدرب الأربعين

خامساً: خطة عمل برنامـج إرشــادى للنهوض بمعارف وممارسيات

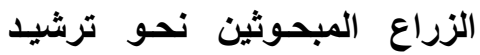

استخدام مياه الرى ونظم إدارتها

بنـاءًا على ما تـم عرضــ لنتائسج الدر اسة

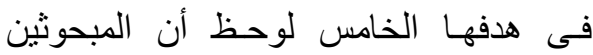

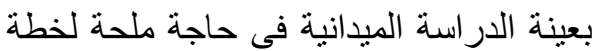

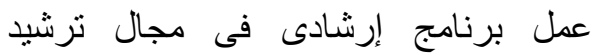

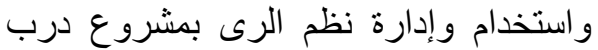

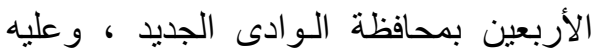

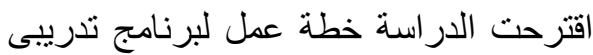

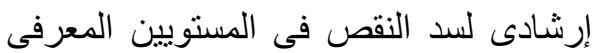

والتنفيذى كما هو موضح بالجدول رقم (9).

المناقثة العامة للنتائج و التوصيات

\section{1 - المناقثة العامة}

فى البداية يجب التنويه بأن هذه الدراسة

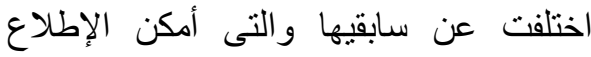
عليها حيث شملت عمليات نرشيد استخدام

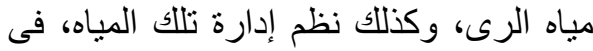

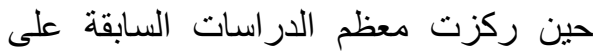
عمليات ترشيد استخدام مياه الرى فقط. كما

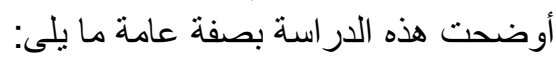

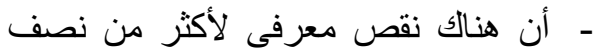

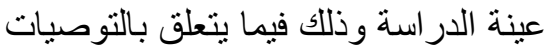
الفنية لترشيد استخدام مياه الرى ونظم بلته

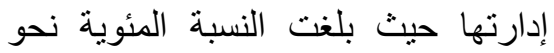

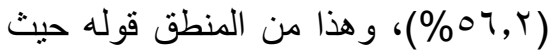

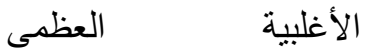

بممارسات ترشيد استخدام مياه الرى ونظم

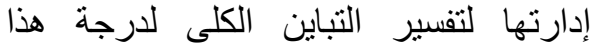
المستوى التنفيذى". ولاختبار صحة هذا الفرض الإحصائى الفئي

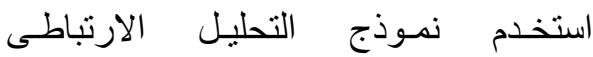

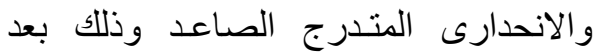

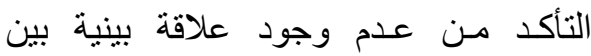
المتغيرات بمصفوفة الارتباط، وقد تبين من عند

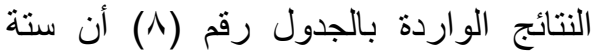
متغير ات من بين المتغير ات المرتبطة معنوياً

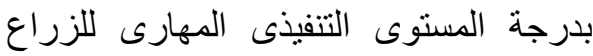

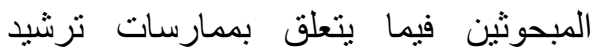
استخدام ميـاه الرى ونظم فئما إدارتها، حيث

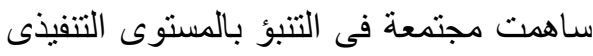

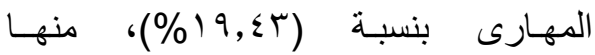

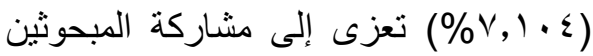

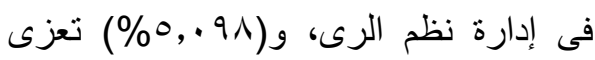

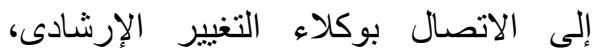

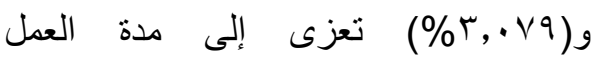

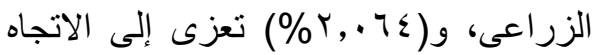

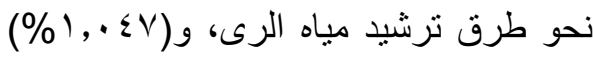

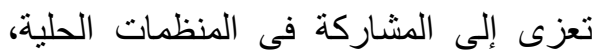

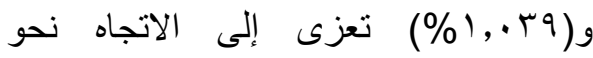
المستحدثات الزر اعية.

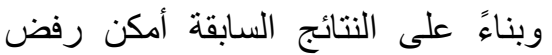

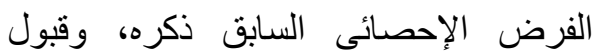
الفرض الإحصائى البديل، و عليه أمكن القول

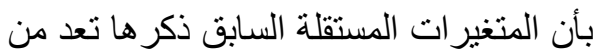

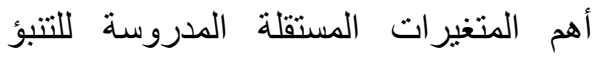
بالمستوى التنفيذى المهارى نحو ممارسات ترشيد استخدام مياه الرى ونظم إدارتها. 
جدول رقم ^: التحليل الارتباطى والانحدارى المتعدد لعلاقة مستوى التغيير فى المستوى

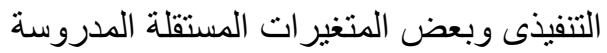

\begin{tabular}{|c|c|c|c|c|c|}
\hline المعنوبة & الانحدارل & 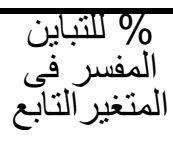 & الارتباطل & المتغير الداخل فى التحليل & الخطوات \\
\hline$* *,, \cdot \vee \wedge$ & • & $V, 1 \cdot \varepsilon$ & $\cdot, r \cdot r$ & مشاركة المبحوثين فى إدارة نظم & الأولى \\
\hline$* * ., .70$ & $\cdot$, ז & $0, .91$ &., .91 & الاتصسال بوكلاء التغيير & 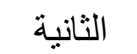 \\
\hline *.,. ו & 1,171 & $r, \cdot \vee q$ & $\cdot, \Sigma \vee V$ & مدة العمل الزراعى & الثالثة \\
\hline$*,, \cdot \varepsilon$ & r, Ir. & $r, \cdot T \varepsilon$ & •, & الاتجـاه نحـو طرق نرشيد مباه & 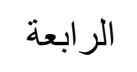 \\
\hline$* *,, 0$ & $\cdot, 7 \cdot 1$ & $1, \cdot \leqslant V$ & سזו, & الرشى الركة فى المنظمات المحلية & الخامسة \\
\hline *., I I &., 171 & $1, \cdot r q$ & $\cdot, 111$ & الزاتجـاه & السـادسة \\
\hline
\end{tabular}

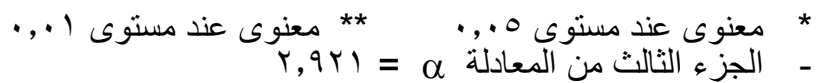

المصدر: عينة الدر اسة الميدانية.

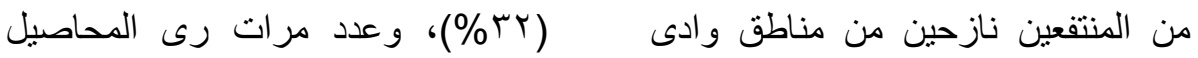

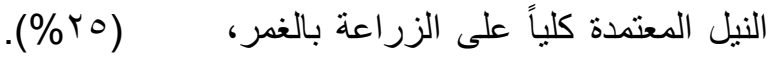

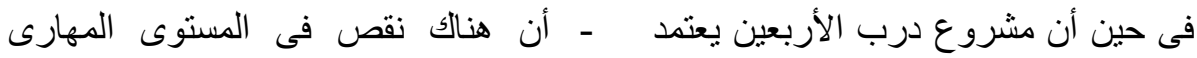
لكافة التوصيات المتعلقة بالممارسة الفعلية على عمليات الرى الحديثة.

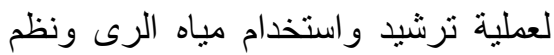

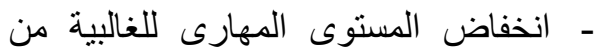

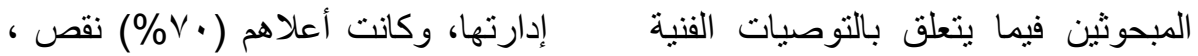

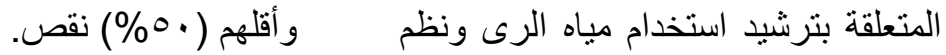

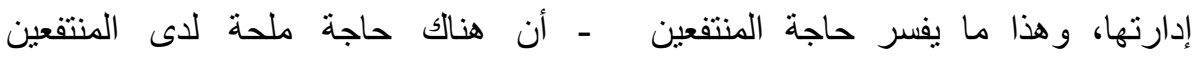

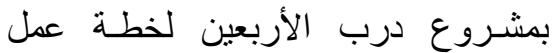
إلى بر امج تدريبية فى هذا الجانب.

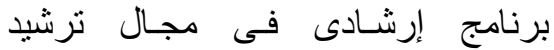

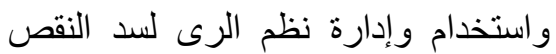

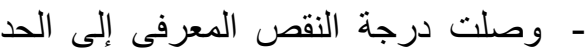
الأقصى فى التوصيات المتعلقة بطرق

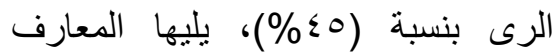

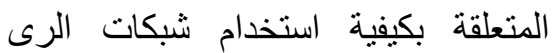


برنامج إرشادى لإستخدام مياه الرى بدرب الأربعين

Arab Univ. J. Agric. Sci., 14(1), 2006 
أحمد ، عفت عبد الحميد ، وفهمى ، مها

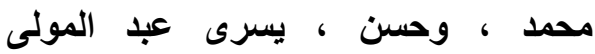

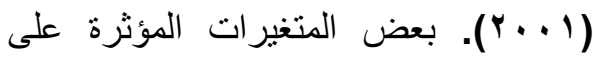

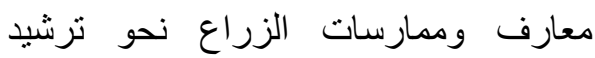

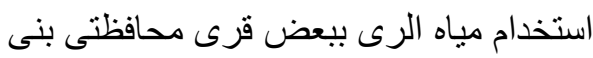

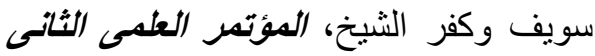
- مستقبل التنمية الزراعية والمجتمعية النية

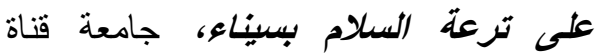

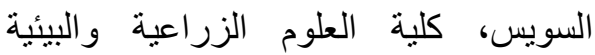

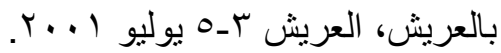

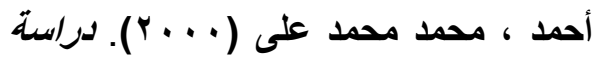

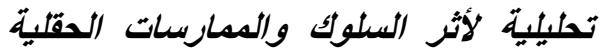

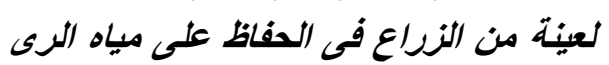

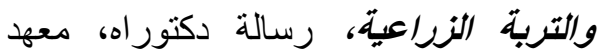

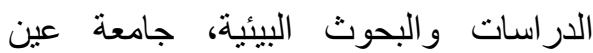

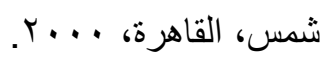

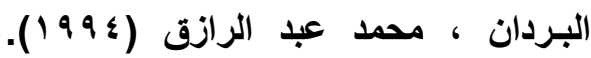

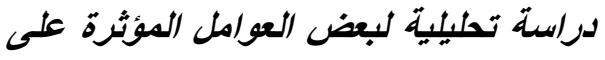
اتجاهات الخريجبن المنتفعين نحو معارسة الرئة

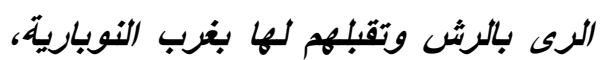

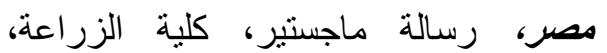

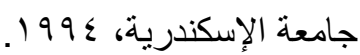

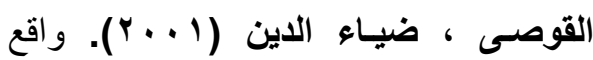
ومستقبل الأمن المائى ومحاوره الثائ الثلاثة،

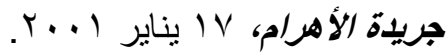

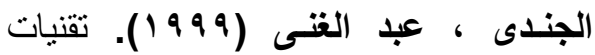

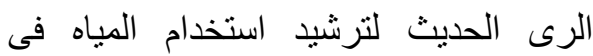

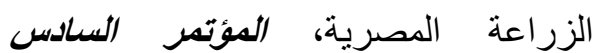
للاراسات والبحوث الفنية، تنمية البيئة

- يجب على المسئولين فى الإدارة العامة

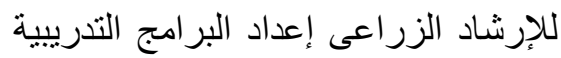

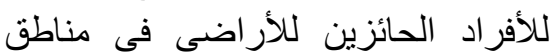
مشابهة والتى تعتمد على الرى لإنى الحديث فيث

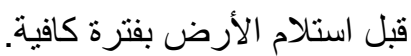
- ضرورةاختيار المرشدين و والقادةالمحليين فى مجال ترشيدالمياه و إدارةنظم الرنمن بين الذين تتوفر فيهم المو اصفات الإيجابية

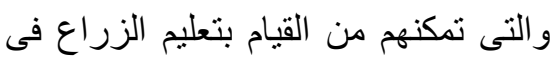

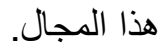

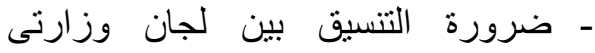

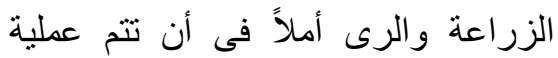
ترشيد الزراع فى مجال الزئ الزتخدام مياه الرى وصيانة شبكاتها بفعالية وتحقى الرن

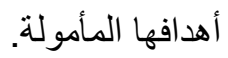

\section{المراجـع}

أبو السعود، خيرى، وحنين، سامية حنا،

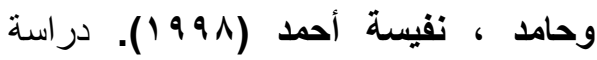
المتغيرات المؤثرة على درجة معرفة وتنفيذ احمدات

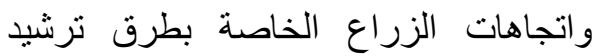

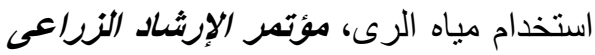

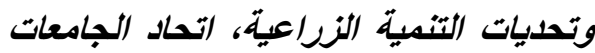

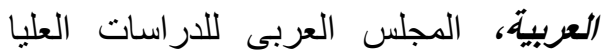

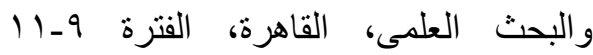
ديسمبر 1991. أبو زيلد ، محمود عبد الحليم (1997 199).

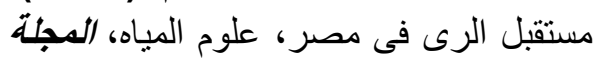


عصمث، محمد حسن، وأنور، حمدى السيد، وعبد الغنى ، كريمان حسن (199^) ). الطرق الإرشادية ومصادر معلومات الزراع الخريجين وبعض خصائصهم الاجتماعية و الاقتصادية و علاقتها بإدر اكهم للمستحدثات التكنولوجية فى مجال ترشيد استخدام مياه الرى بقرى الفشن وسمالوط، مؤتمر الإرشاد

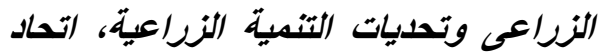

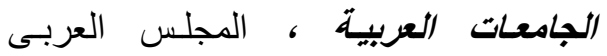

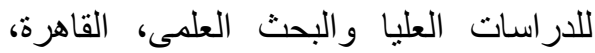

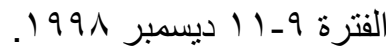
ناثد ، نبيل فوزى (9 9 9 ( ). سياسة تطوير

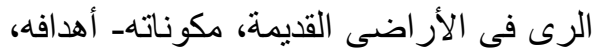

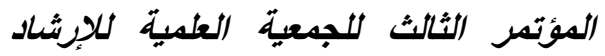
الزراعى، دور الإرشاد الزراعى فى ترشيد استخدام مياه الرى فى أراضى الرى الإدى الرى القديم

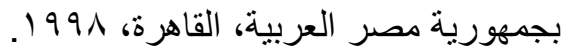

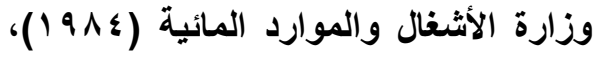
التنمية الزراعية ودور معهد بحوث توزيع والثيع المياه وطرق الرى، مؤتهر البحث العلمهى في إنه

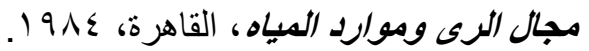
William, P. and E.F. Burton (1982) Mass Media System and Effects. $2^{\text {nd }}$, Ed., Rinehart and Winston, New York, 1982.
الصصراويتة، القاهرة، الفترة 9-V نوفمبر .1999

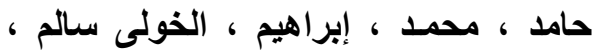

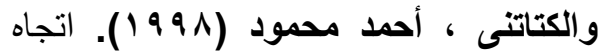

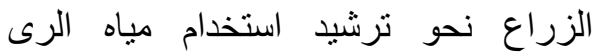

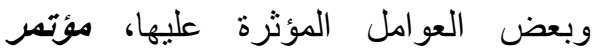
الإرشاد الزراعى وتحديات المستقبل للتنمبية

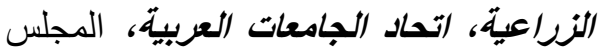

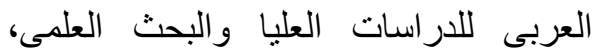

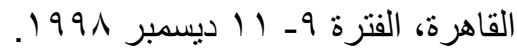
سعد ، كمال فريد (999 199). آفاق المنظور المائى العربى للقرن الحادى و العشرين،

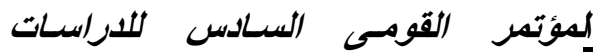
والبحوث الفنية، تثمبية البيئة الصحراويةه،

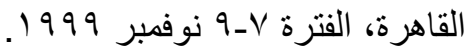

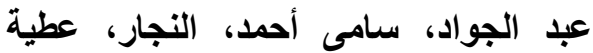
أحمد، والسيد، أحمد حبيش (1 . . ب)، الأثر

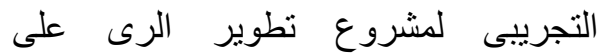
المعرفة والتفيذ فى مجال ترشيد استخدام مياه الرى بمحافظتى كفر الثيخ، و البحيرة بمصر، المؤتمر العلمهى الثانس- مستقبل

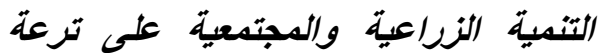
السلام بسيناء، جامعة قناة السويس، كلية

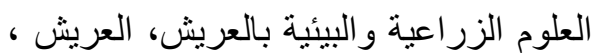

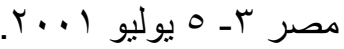


Arab Univ. J. Agric. Sci., Ain Shams Univ., Cairo, 14(1), 1-31, 2006

\title{
FARMERS NEED OF AN EXTENSION PROGRAM TO RATIONALIZE IRRIGATION WATER AND MANAGE NEW IRRIGATION SYSTEMS IN “DARB AL-ARBE'EN" PROJECT, AL-WADY AL-GADID GOVERNORATE
}

[1]

\author{
Moustafa Muawad, M.M. ${ }^{1}$
}

\begin{abstract}
The study aimed at identifying both knowledge and skill levels of farmers in regard of technical recommendations of rationalizing irrigation water use and its various management systems, determine the deficit in their knowledge and skills degree in that regard as a step to propose an extension program that hope to remedy this gap. The study was conducted in Al-Wady Al-Gadid governorate on beneficiaries of "Darb Al-Arbe'en" project, with a random sample of 160 represent about $25 \%$ of total beneficiaries (640). Data were collected through a personal interview questionnaire during (August-September) 2005, and the following statistics were used: frequencies, percentages, arithmetic mean, standard deviation, simple correlation coefficients, $\mathrm{F}$ test and multiple regression analysis (Stepwise).
\end{abstract}

\section{The results revealed the following}

- More than half the interviewees $56.3 \%$ had low knowledge in regard of technical recommendations of rationalizing irrigation water use and its management systems, and about $20.5 \%$ of total interviewees had no knowledge in that regard.

- About 51.3\% of interviewees had low implementation skills in regard of technical recommendations of rationalizing irrigation water use and its management systems, whereas about $5 \%$ of total interviewees were highly skilled.

- In general there was knowledge deficit in about seven groups of technical recommendations of rationalizing irrigation water use and its management systems ranged between $17 \%-45 \%$ of total knowledge.

1- Agriculture Extension Rural Sociology and Agriculture Extension Department, Faculty of Agriculture, Ain Shams University, Shoubra El-Kheima, Cairo.

(Received November 26, 2005)

(Accepted December 7, 2005)

Arab Univ. J. Agric. Sci., 14(1), 2006 
- There was a general skill deficit among interviewees in regard of technical recommendations of rationalizing irrigation water use and its management systems ranged between $50 \%-70 \%$ of total skills.

- Interviewees essentially need an extension program in rationalizing irrigation water use and managing new irrigation systems and a plan of action was sited in the study.

- Finally, the study recommended the necessity to prepare excessive training programs to beneficiaries from the project in order to increase their knowledge and skills in that regard.

Key words: Farmers need, Extension program rationalize irrigation Water, Darb AlArbe'en Project

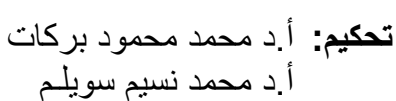

